\title{
THE CHALLENGES OF USING VIDEO CONFERENCING IN EDUCATIONAL SUPERVISION IN THE SULTANATE OF OMAN: EDUCATIONAL SUPERVISORS' PERSPECTIVES
}

\author{
تحديات استخدام مؤتمرات الفيديو في الإثراف التربوي من وجهة نظر المشرفين \\ التربويين بسلطنة في الإنير عمان \\ محمد بن حمد الندابي
}

Mohammed Hamed Alnadabi ${ }^{1 *}$ and Muhammad Sabri Bin Sahrir ${ }^{2}$

${ }^{1}$ Ph.D. Candidate in Teaching Technology, Department of Curricula and Teaching Methods,

Faculty of Education, International Islamic University Malaysia (IIUM): mohd2ndabi@moe.om

${ }^{2}$ Assoc. Prof. Dr. at the Kulliyyah of Education, International Islamic University Malaysia (IIUM);

muhdsabri@iium.edu.my

${ }^{*}$ Corresponding author

\begin{abstract}
This paper aims to discuss the difficulties of using videoconferencing technology in supervisory practices, from an educational supervisory perspective. Whereas, although video conferencing technology is important; The number of educational supervisors who use it is not commensurate with its value and significance, as studies have reported on this technology, perhaps as a new technology. Therefore, the study aimed: to discuss the technical challenges, and the human challenges facing the use of videoconferencing technology in supervision. The researcher used the descriptive and analytical method, whereby a questionnaire was designed consisting of two axes: The first for technical difficulties consists of (11) phrases, and the second for human difficulties consists of (9) phrases. It was applied to a sample of (322) educational supervisors. The study found the following results: The existence of material obstacles that came to a large extent about the use of videoconferencing technology in supervisory operations, as the weakness of the Internet in some remote areas came in first place with the highest arithmetic average of (4.19), followed by "weak infrastructure of schools and directorates. Educational governorates "with an average of (4.08). Followed by the presence of human obstacles that came with a moderate degree regarding the use of video conferencing technology in supervisory operations. Lack of training in employing videoconferencing technology" came in first place with the highest arithmetic average of (3.96). The study includes a set of recommendations, including preparing an integrated guide to explain the mechanism of activating video conferencing in supervisory work. It includes analyzing and studying the psychological, technical and material factors facing the activation of video conferencing.
\end{abstract}

Keywords: videoconferencing, educational supervision, educational supervisor.

$$
\text { الملخص }
$$

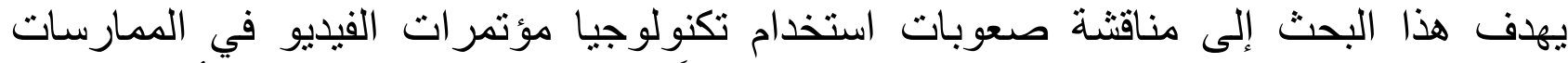

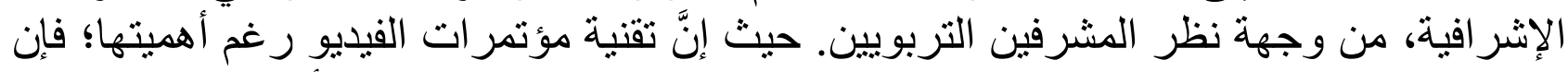
عدد المقبلين و المستخدمين لها من المشرفيين التربويين لا يتتاسب مع قيمتها و أهميتها، كما ذكرته 
الدراسات حول هذه التقنية، ربما كونها تقنية جديدة. لذا هدفت الدراسة: مناقثة التحديات الفنية،

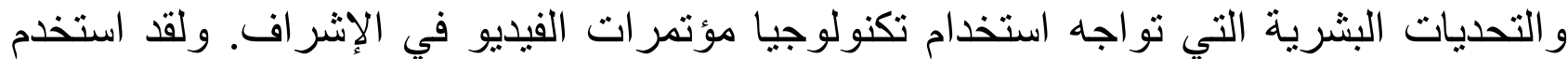

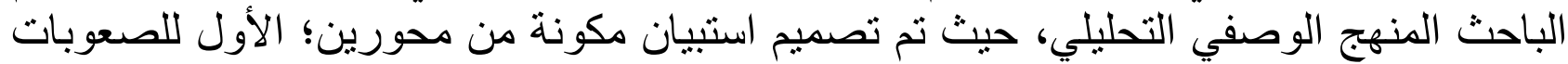

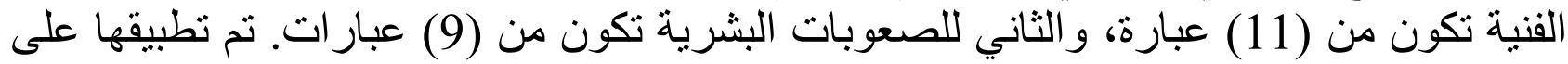

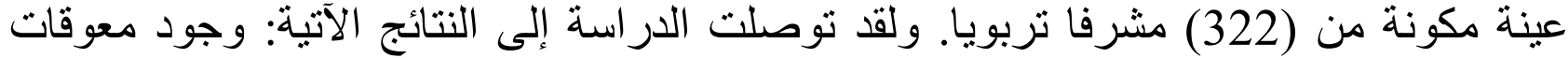

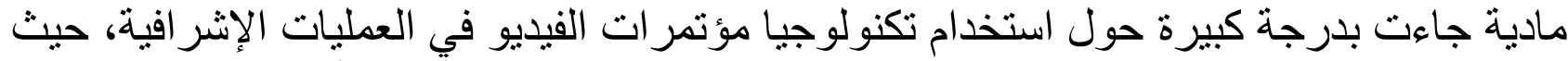

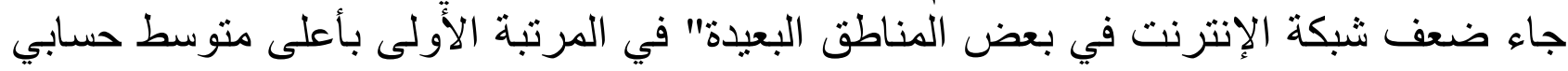

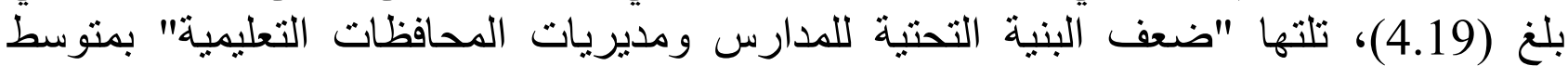

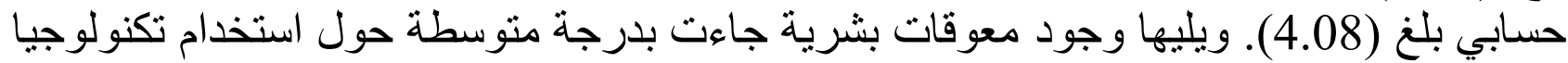

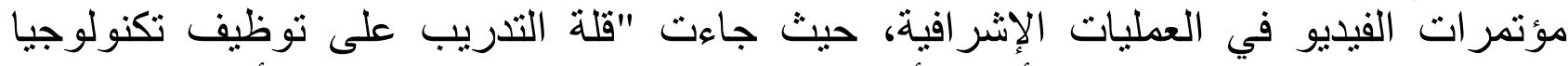

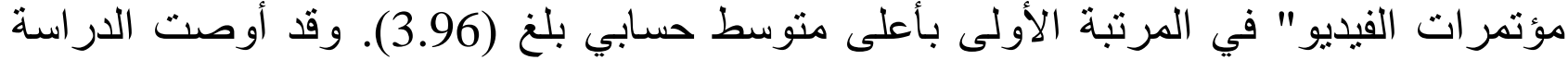

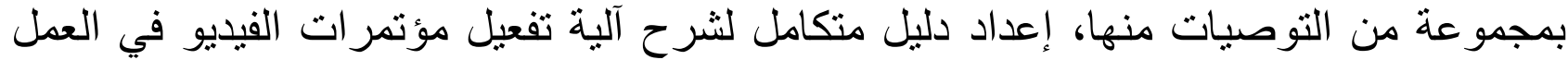

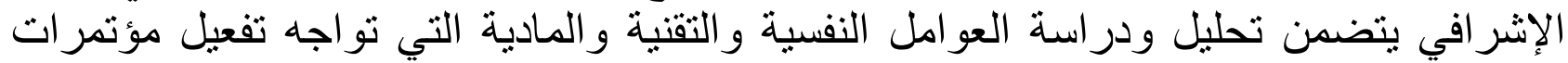
الفيديو. كلمات مفتاحية: مؤتمر ات الفيديو، الإشر اف التربوي، المشرف التربوي.

المقدمة

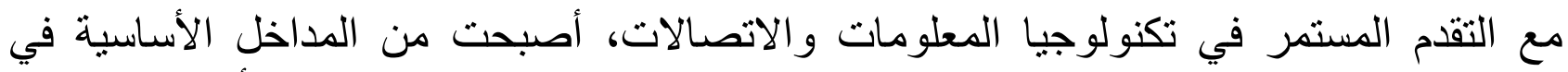

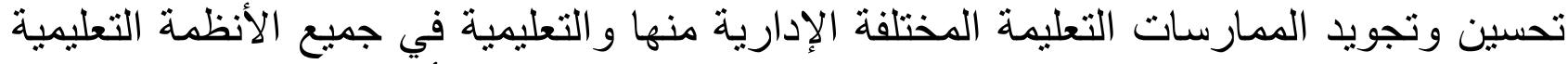

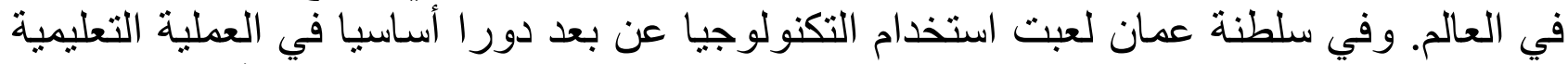

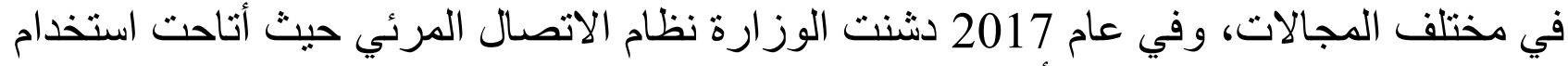

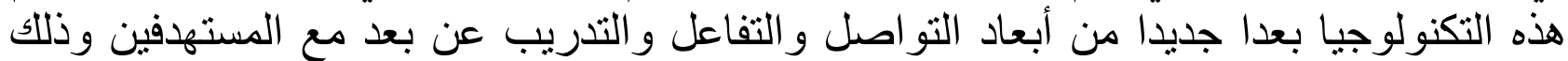

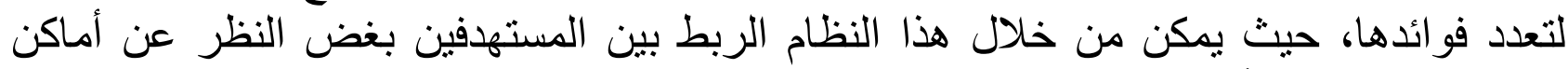

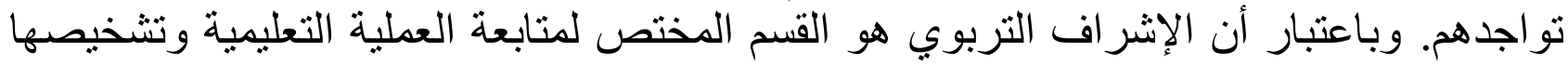

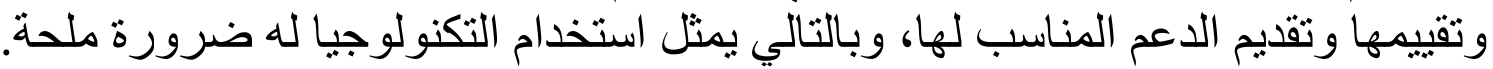

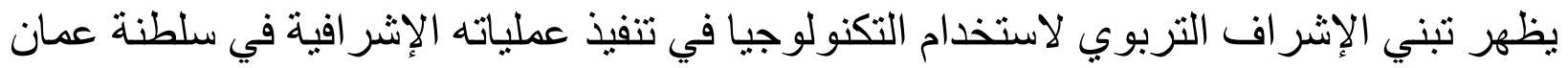

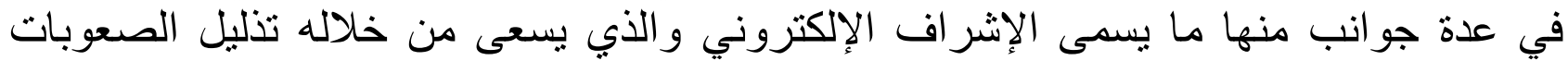

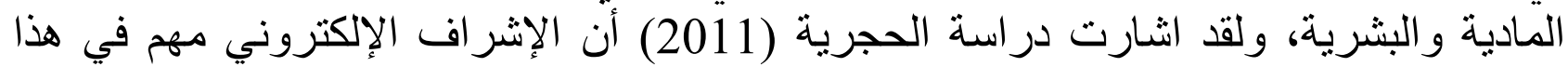

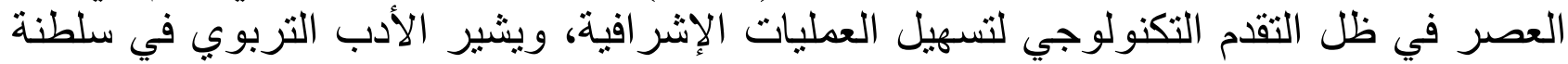

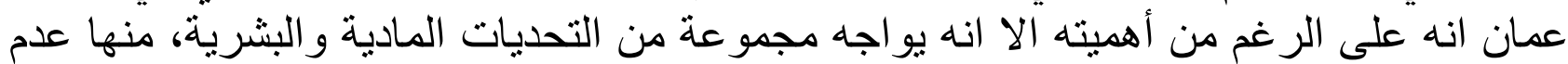

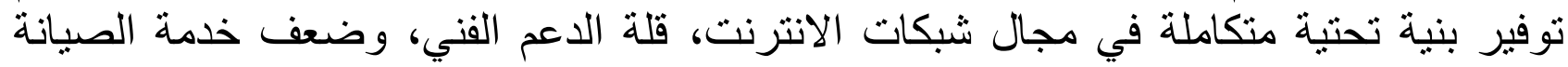

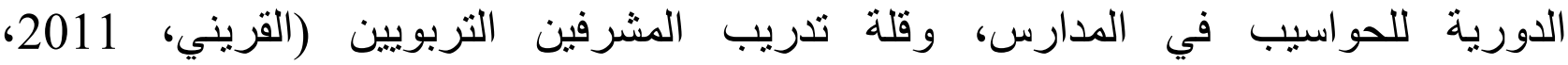
الكلباني،2016، الكندي، الكية 2017، الوردية، 2017). وفي عام 2017م بدأ الإشر اف التربوي في توظيف تكنولوجيا مؤتمرات الفيديو في تتفيذ بعض 


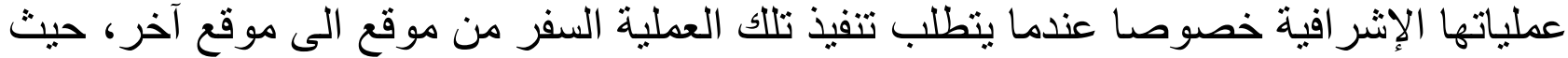

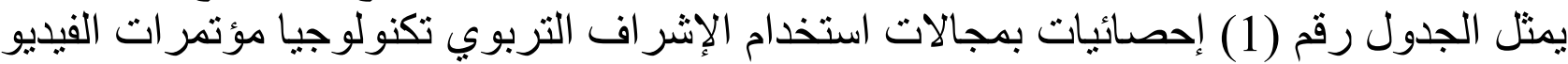

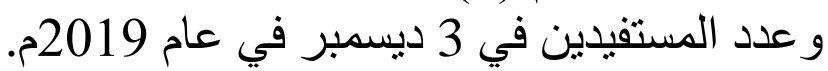
جدول (1) استخدام تكنولوجيا مؤتمر ات الفيديو في الإشر اف التربوي و عدد المستفيدين

\begin{tabular}{|c|c|c|}
\hline عدد المستفيدين & مجالات الاستخدام & م \\
\hline 85 & البر امج و الورش التدريبة & 1 \\
\hline 2072 & اللقاءات & 2 \\
\hline 315 & الفعاليات الأخرى & 3 \\
\hline 3523 & المجموع & \\
\hline
\end{tabular}

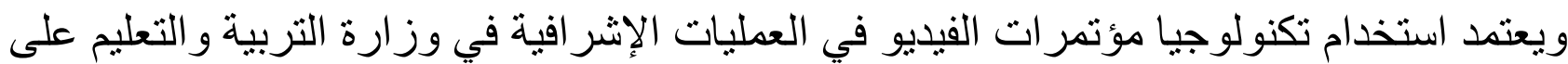

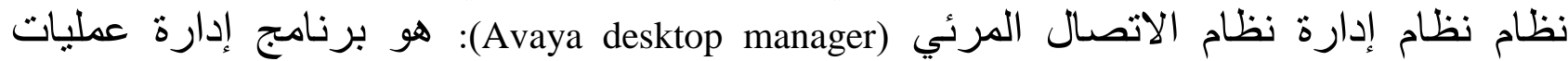
الاتصال مع المحافظات التعليمية، يمكن مشرف القات القاعة من التحكم الكامل في عملية الاتصال

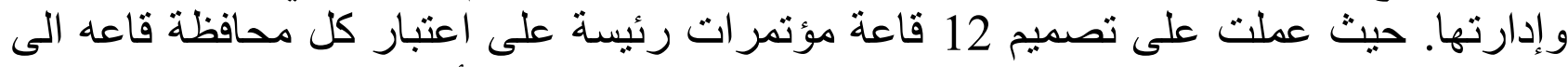

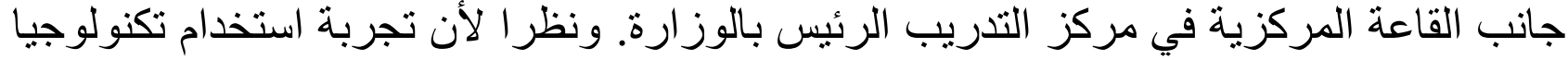

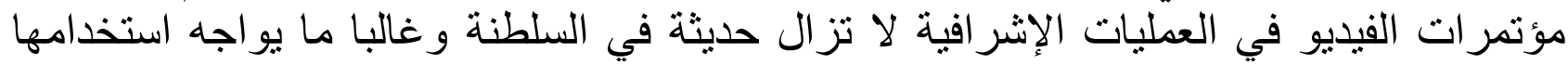

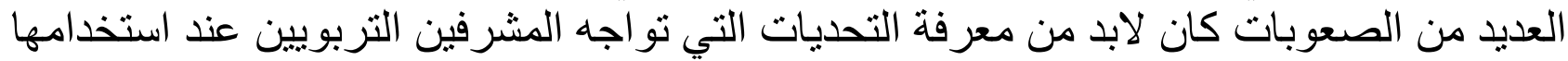

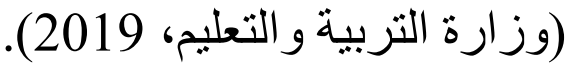

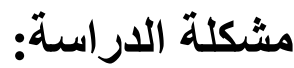

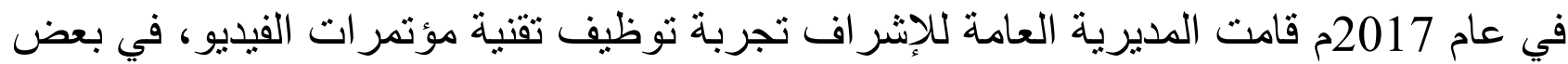

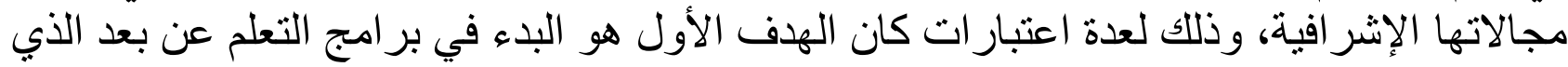

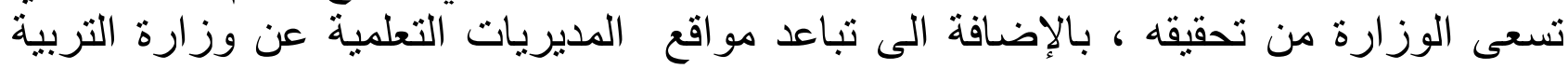

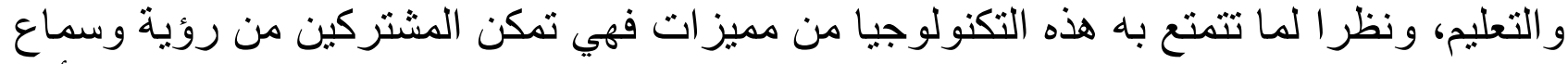

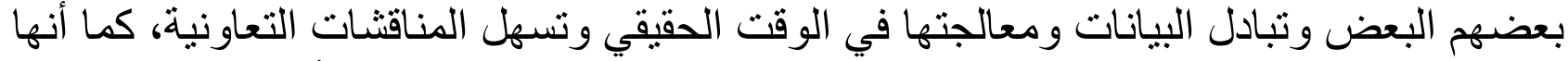

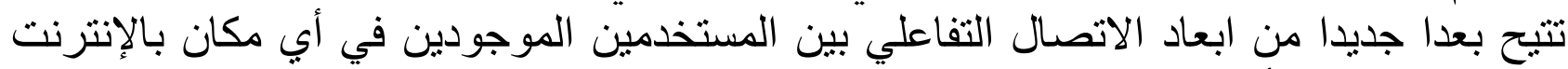

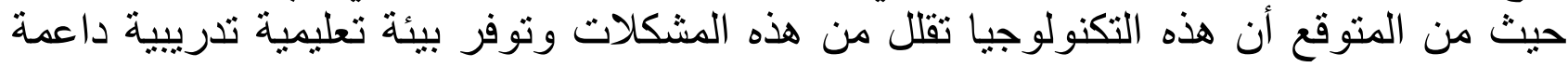
لقدر ات المشرفين (سفر ، 2008).

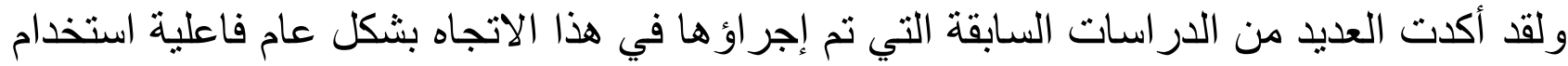

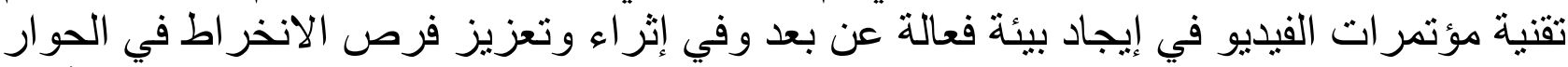

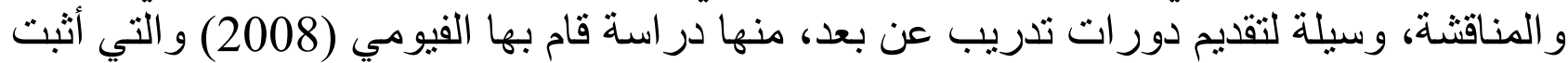

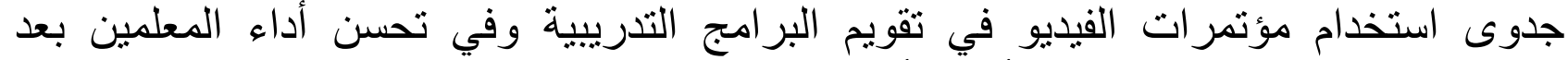

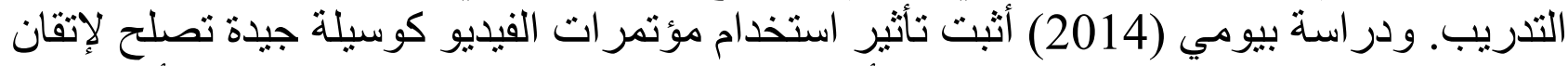
مفهم التدريب المستمر للمعلمين دون عائق أو مانع بغض النظر عن موقهم الجغر افي. و أما در اسة لاتفان 


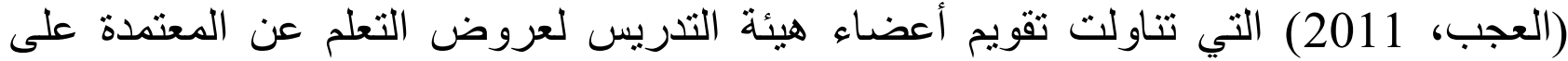

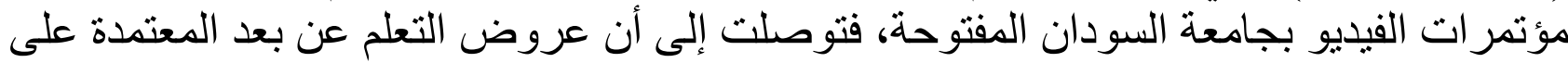

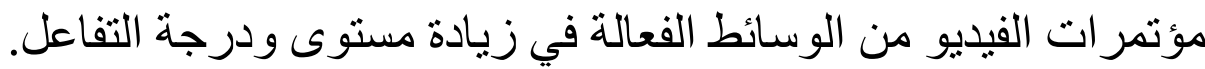
ولكن على الرغم من جدوى استخدام تكنولوجيا مؤتمرات الفيديو في العملية التعليمية بصفة عامة فئة

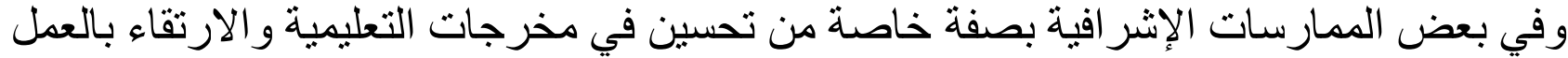

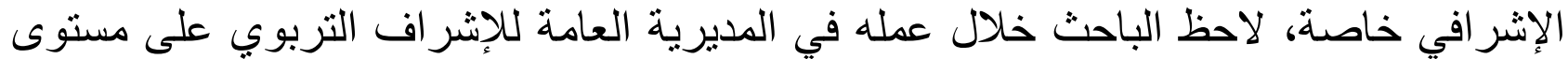

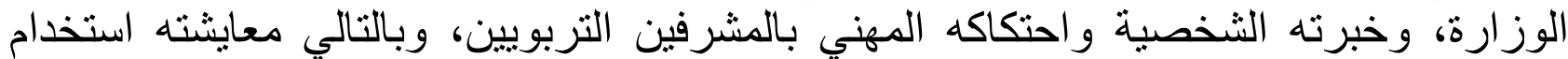

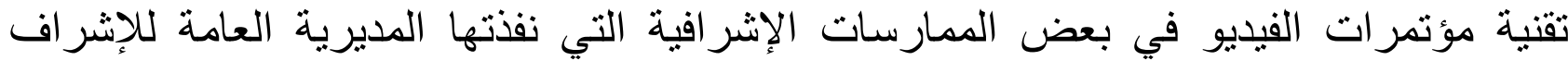

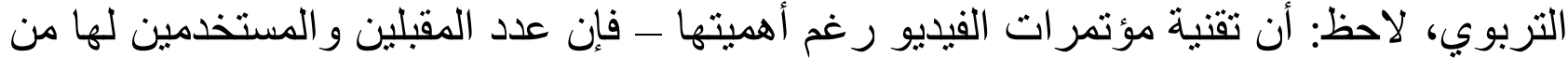

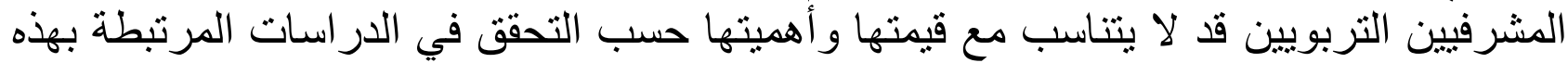

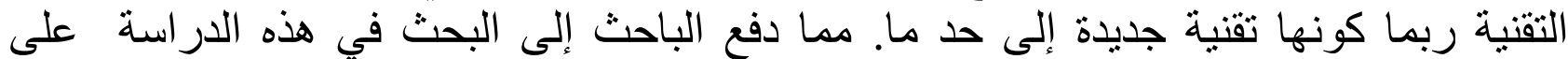

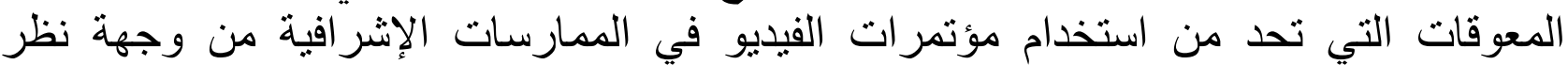
المشرفين التربوبين أنفسهر .

وفي هذا الإطار يصوغ الباحث مشكلة البحث في السؤال الرئيس: ما معوقات استخدام تكنولوجيا مؤتمر ات الفيديو في الممارسات الإشر افية من وجهة نظر المشرفين التربو التين؟

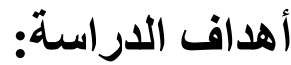

تضمنت الدر اسة الأهداف التالية: 1- الكثف عن المعوقات المادية التي يمكن أن تعترض استخدام مؤتمرات الفيديو في مجالات الترني الإشر اف من وجهة نظر المشرفين التربويين. 2- الكثف عن المعوقات البشرية التي يمكن أن تعترض استخدام مؤتمرات الفيديو في مجالات الإشر اف من وجهة نظر المشرفين التربوبين.

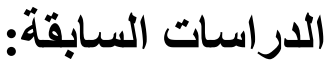

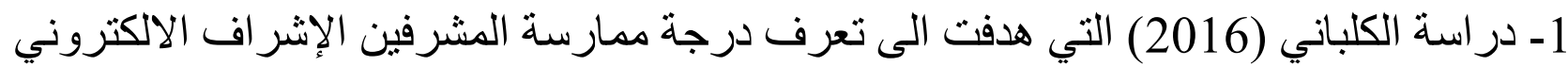

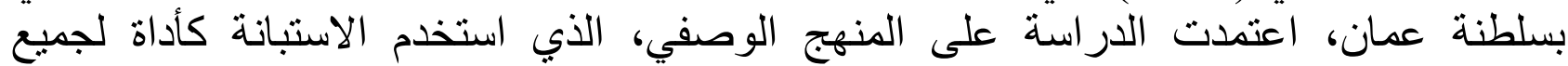

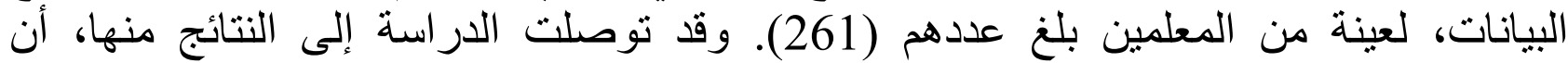
المشرفين يمارسون الإشر اف الإلكتروني بدرجة كبيرة، جاءت مشكلة البنية التحتية في ممارسة

$$
\text { الإشر اف الإلكتروني بدرجة كبيرة الإثناف }
$$

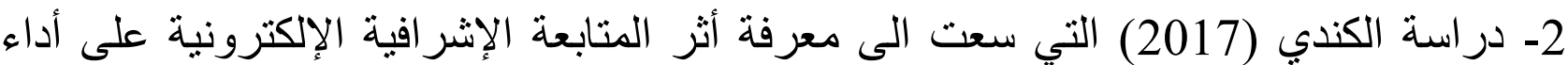

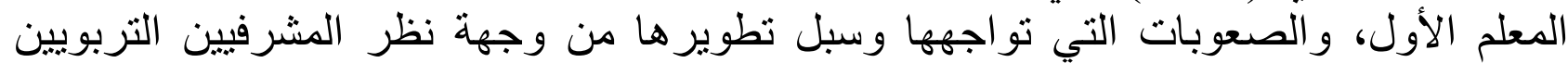

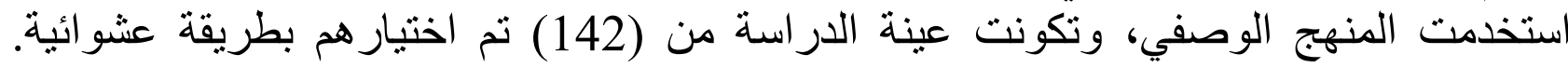
توصلت الدر اسة إلى وجود صعوبات كبيرة ومنوسطة حول المتابعة الإشر افية الإلكترونية وكان الترنة

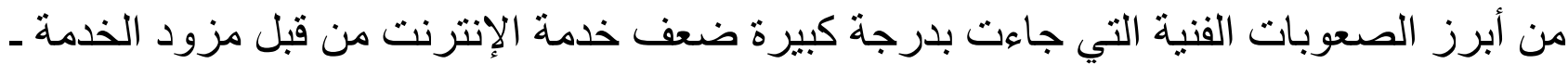
قلة الدعم الفني، وضعف المبرة خدمة الصيانة الدورية للحو اسيب. 3- الزهر اني (2013) بدر اسة بعنو ان فاعلية مؤتمر ات الفيديو في تتمية الكفايات المهنية للقيادات 


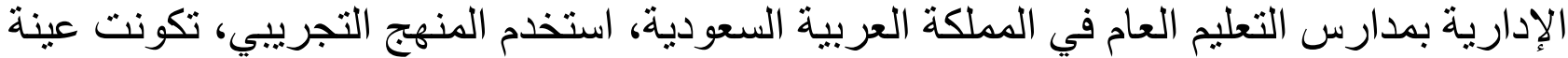

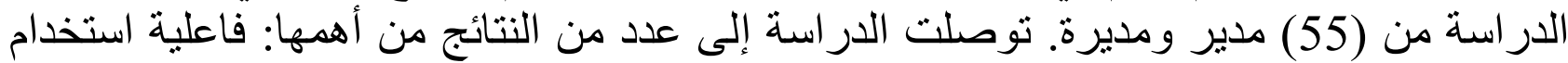

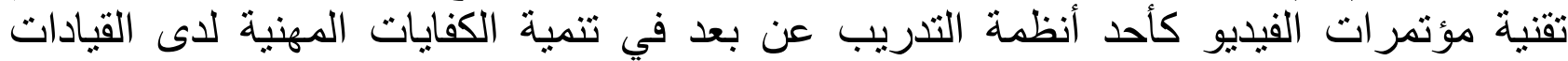

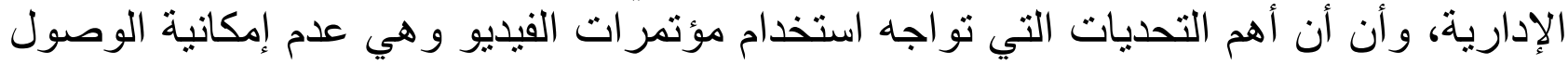
إلى الإنترنت، وضعف الدن الدم الفني.

4- (2014)

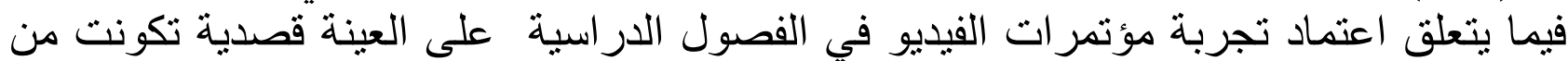

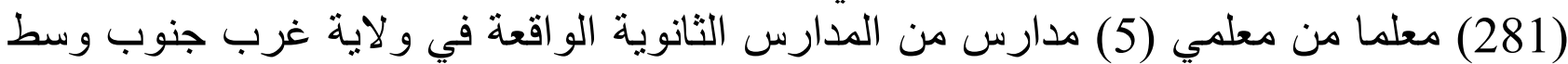

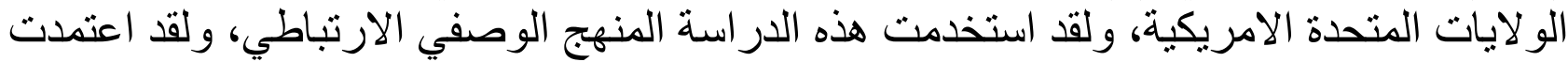

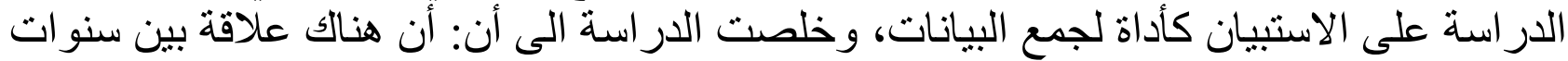

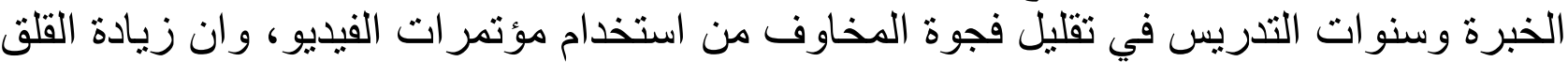

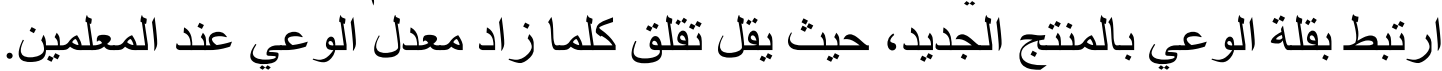

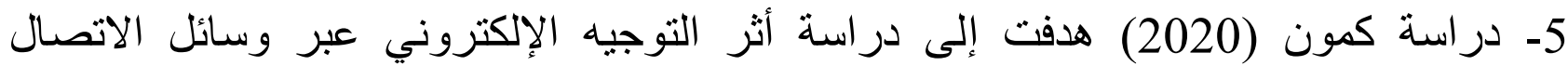

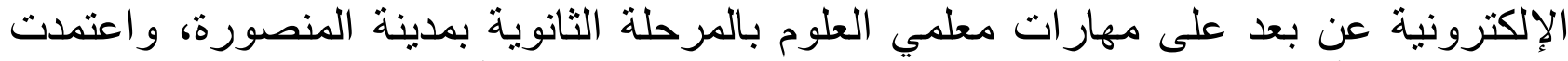

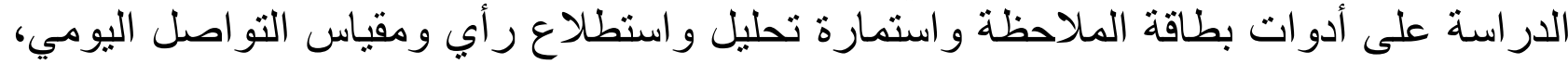

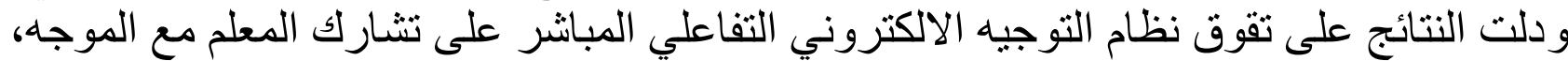

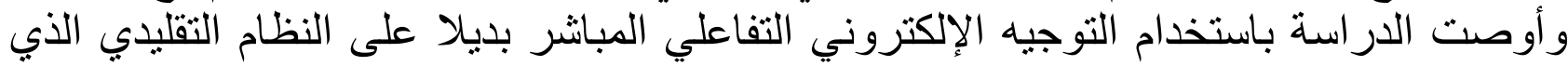

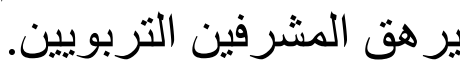
التعليق على الاراسات السابقة:

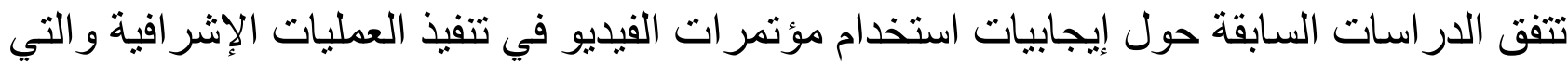

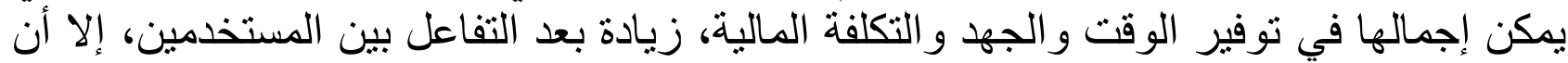

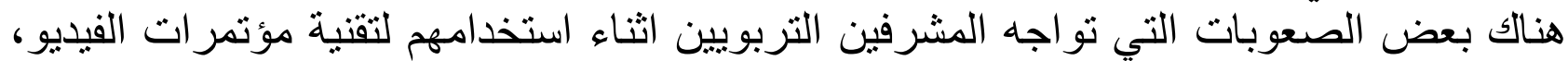

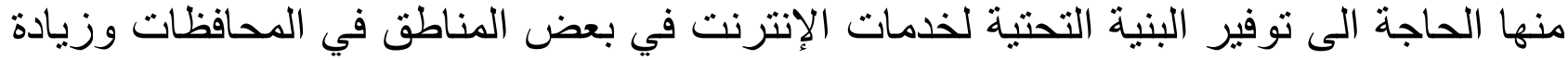

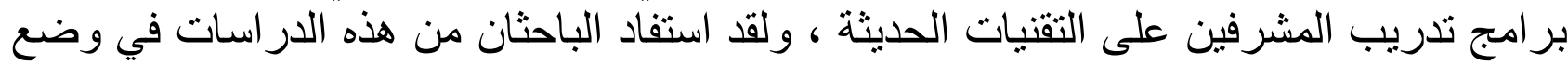

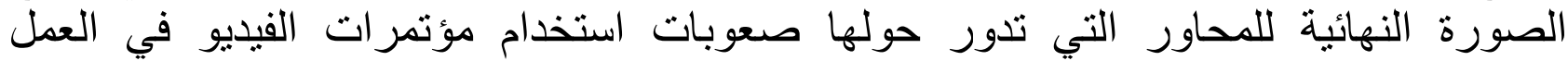

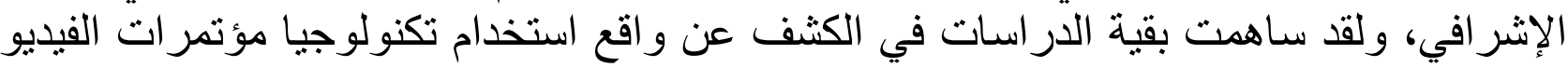
في مجالات العملية التعليمة ومدى توافر المتطلبات اللازمة لتسهيل استخدامها.

\section{منهجية الدراسة وإجراء|تها:}

المنهج:

لقد اتبع الباحثان المنهج الوصفي التحليلي هو المنهج المناسب لأهداف لهذه الدراسة ولقد وصفه

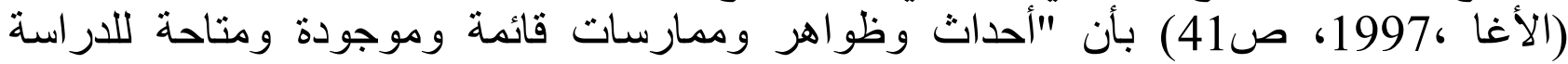

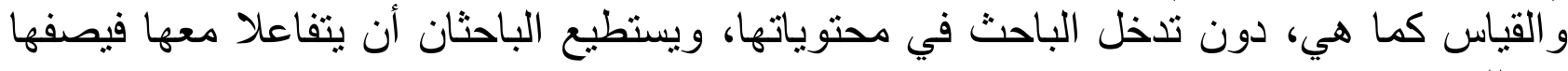


تألف مجتمع الدراسة المشرفين التربويين في وزارة التربية والتعليم بسلطنة عمان - المشرفين

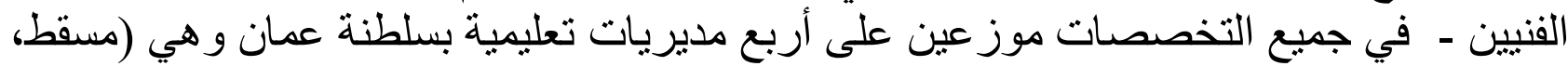

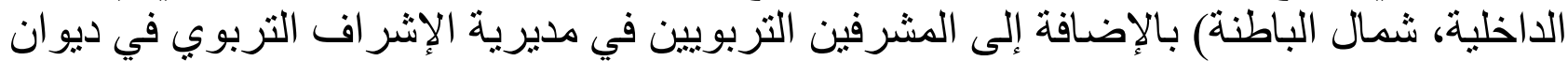

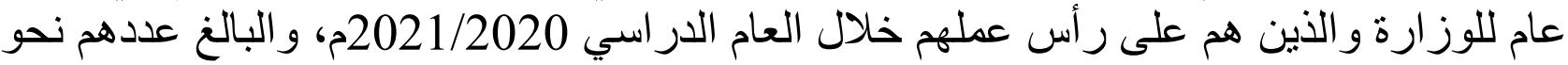

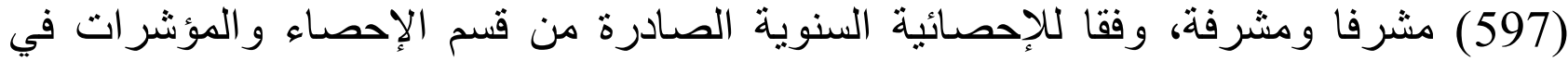

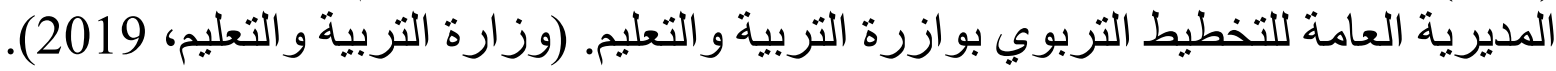

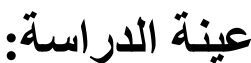

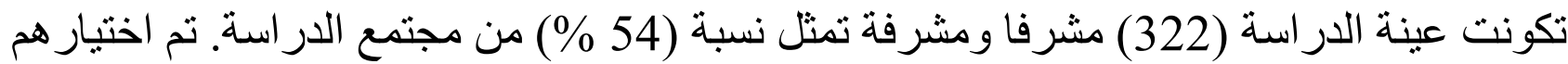

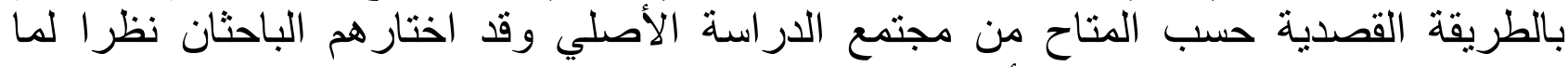
يمتلكونه من خبره في مجال الأساليب الإثرافية والمفهوم الرئيس ويمكنهم إثراء الألئ الدراسة،

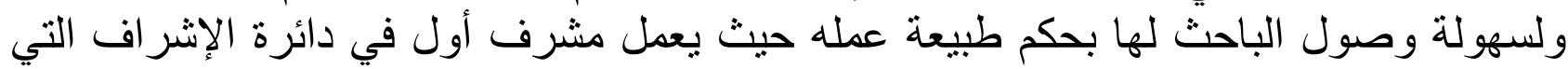
تمثل الاشر اف المركزي في الوزارة، حيث قام الباحثان بحصر هم وتوزيع الأداة عليهم.

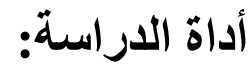

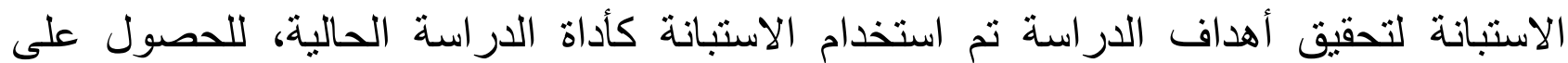

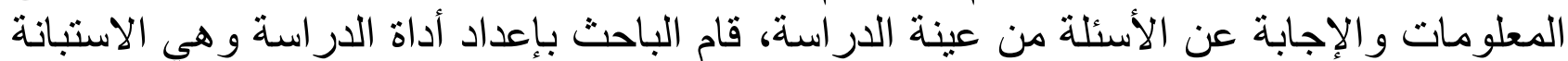

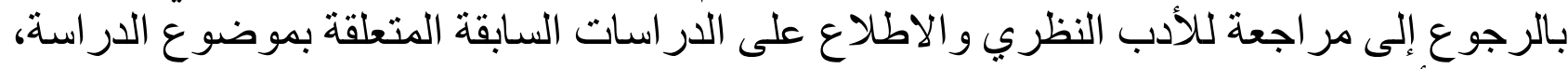

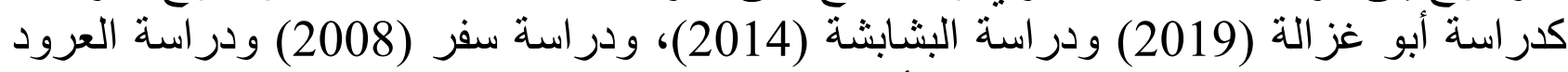

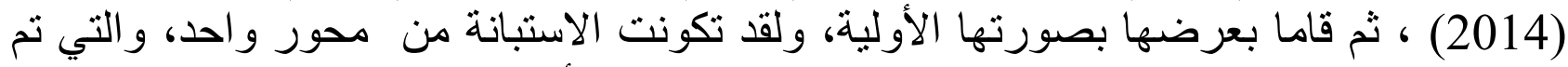

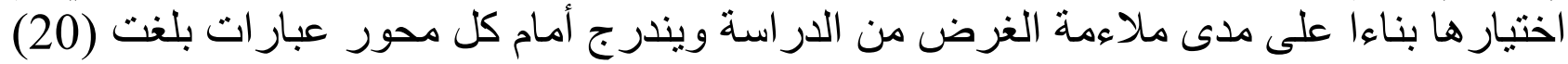

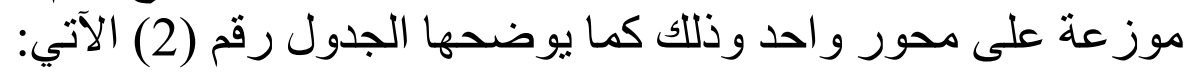
جدول (2) محاور الاستبانة وفقر اتها

\begin{tabular}{|c|c|c|c|}
\hline ألعبار اتم & عدد العبارات & الأبعاد & المحاور \\
\hline $11-1$ & 11 & 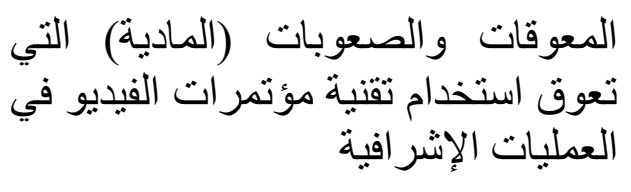 & المحور الأول \\
\hline $20-12$ & 9 & 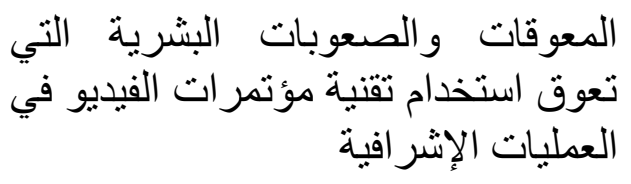 & الثاني \\
\hline 20 & 20 & المجموع & \\
\hline
\end{tabular}

الصدق الظاهزي (صدق المحكمين):

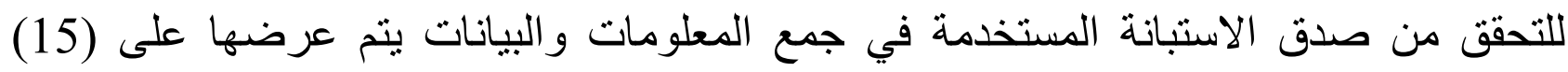

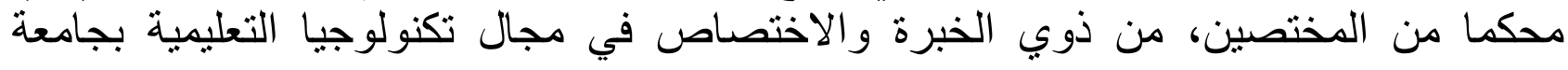


السلطان قابوس و الجامعة الثرقية في سلطنة عمان، بالإضافة مشرفو العموم و المشرفيين الأوائل،

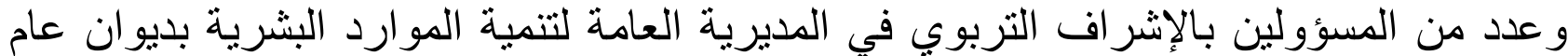

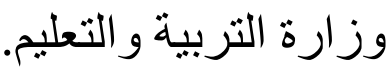

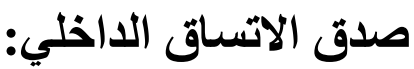

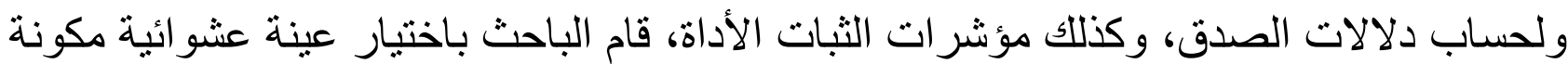

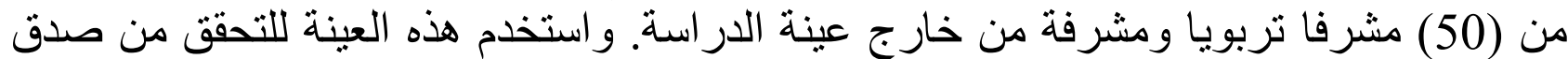

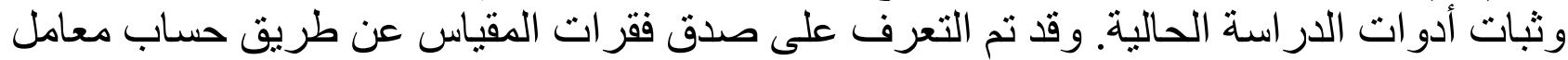

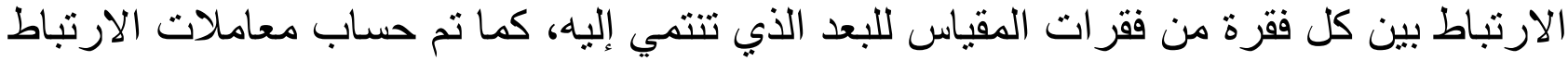

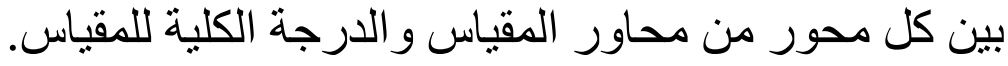
جدول (3) معاملات الارتباط بيرسون لعبار ات محوري الاستبانة مع الدرجة الكلية (العينة الاستطلاعية: ن=50)

\begin{tabular}{|c|c|c|c|}
\hline \multicolumn{2}{|c|}{ المحور الأول } & \multicolumn{2}{|c|}{ المحور الأول } \\
\hline معامل ارتباط & رقم الفقرة & معامل ارتباط & رقم الفقرة \\
\hline 0.773 & 12 & 0.658 & 1 \\
\hline 0.602 & 13 & 0.747 & 2 \\
\hline 0.541 & 14 & 0.686 & 3 \\
\hline 0.613 & 15 & 0.576 & 4 \\
\hline 0.731 & 16 & 0.407 & 5 \\
\hline 0.495 & 17 & 0.776 & 6 \\
\hline 0.605 & 18 & 0.683 & 7 \\
\hline 0.427 & 19 & 0.650 & 8 \\
\hline 0.549 & 20 & 0.572 & 9 \\
\hline & & 0.779 & 10 \\
\hline & & 0.630 & 11 \\
\hline
\end{tabular}

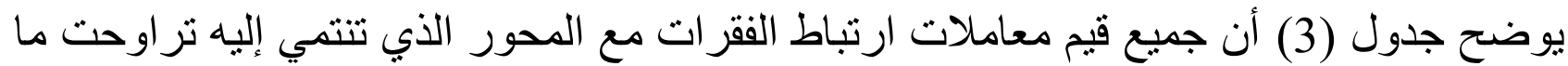

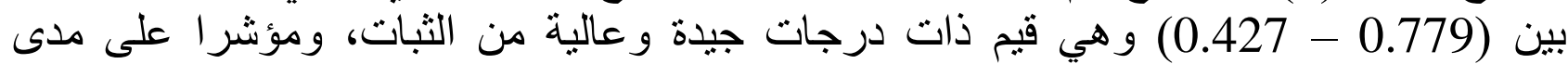

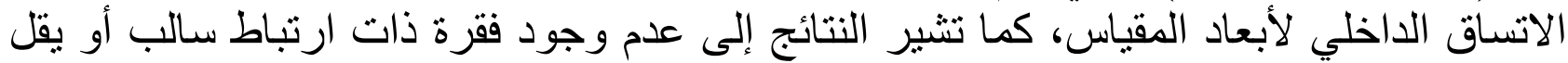

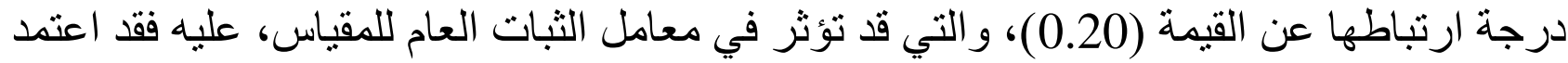


الباحثان جميع فقر ات المقياس و عددها (20) فقرة لأغر اض تطبيق المقياس على عينة الدر اسة.

جدول (4) معاملات الثبات ألفا كرو نباخ لمحاور الدر اسة (العينة الاستطلاعية: ن=50)

\begin{tabular}{|c|c|c|}
\hline معامل الثبات & عدد البنود & المحور \\
\hline 0.936 & 20 & 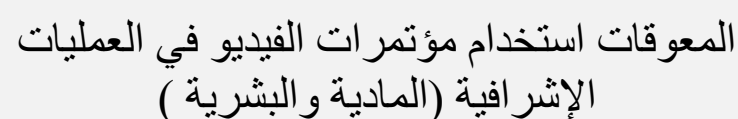 \\
\hline
\end{tabular}

يتضح من الجدول (4) أن معامل الثبات بطريقة ألفا كرو نباخ العينة الاستطلاعية: (ن=50) (50) عال

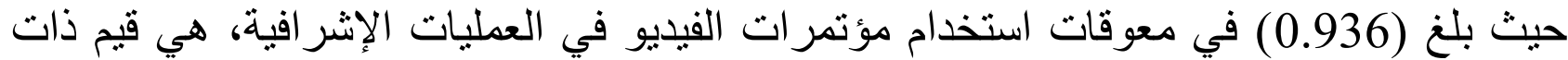

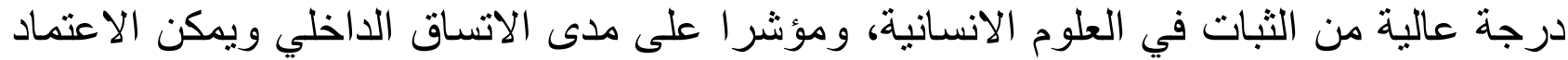

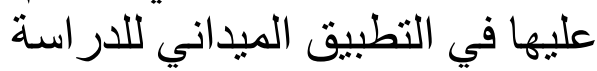
أساليب المعالجة الإحصائية لأداة الدراسة: الأنة

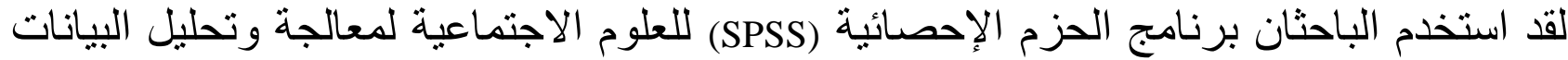

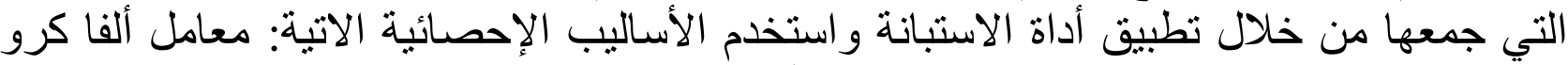

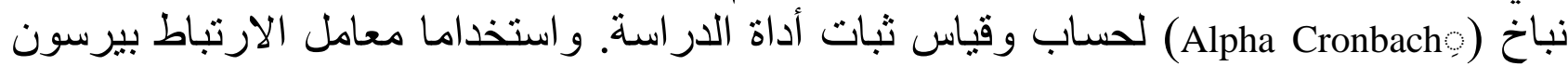
(Pearson)

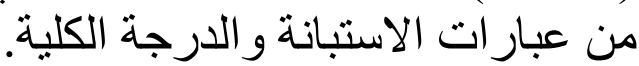

نتائج الدراسة ومناقشتهها وتفسير ها:

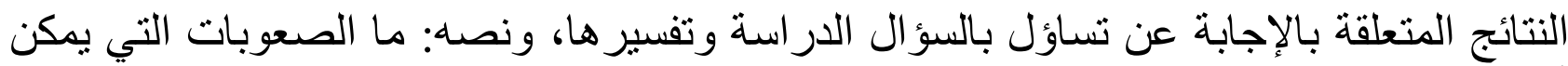

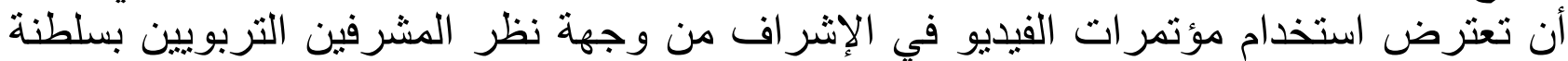

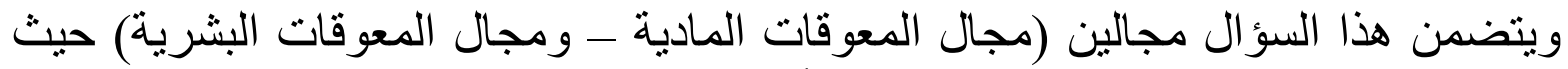

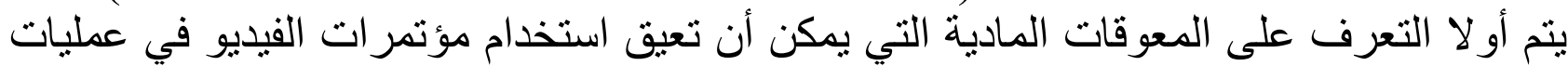
الإشر اف من وجهة نظر المشرفين التربوبين في سلطنة عمان.

وللإجابة عن هذا السؤال، تم استخر اج المتوسطات الحسابية و الانحر افات المعيارية لتقديرات عينة

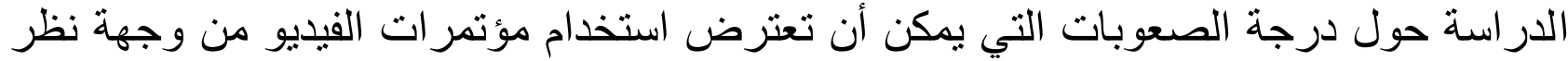

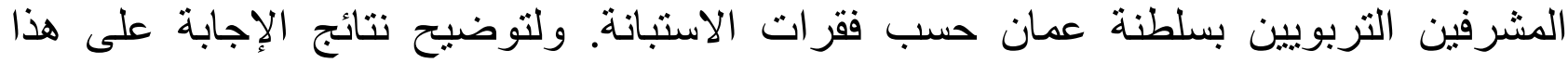

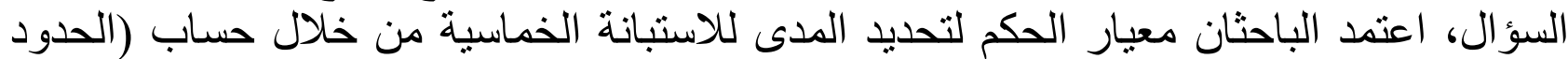
الدنيا و العليا) ثم حساب المدى (أعلى قيمة_ أقل قيمة) = (5- 1-

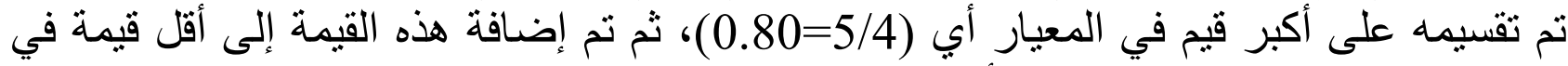
المعيار و هي (0.80) لتحديد الحد الأعلى لهذه الفئة، كما هو موضح في في في الجدول الآتي:

جدول (5): معيار الحكم على نتائج السؤال الثالث 


\begin{tabular}{|c|c|}
\hline الارجة & المدى الم \\
\hline ضعيفة جداً & من 1 إلى 1.79 \\
\hline ضعيفة & من 1.80 إلى 2.59 \\
\hline متوسطة & من 2.60 إلى 3.39 \\
\hline كبيرة & من 3.40 إلى 4.19 \\
\hline كبيرة جداً & من 4.20 إلى 5 \\
\hline
\end{tabular}

المعوقات المادية:

جدول (6) استجابات المشرفين التربويين لتحديد المعوقات المادية مرتبة تنازليا

\begin{tabular}{|c|c|c|c|c|c|}
\hline 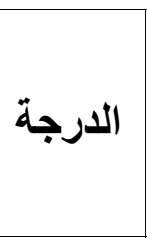 & الأحرا & المستوسط & 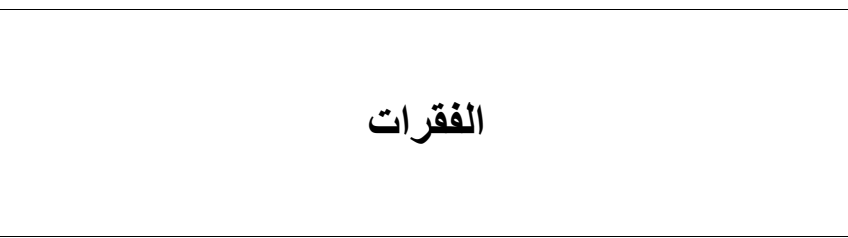 & 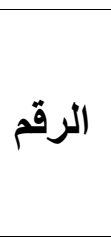 & الرتبة \\
\hline كبيرة & 0.55 & 4.19 & ضعف شبكة الانترنت في بعض المناطق البعيدة. & 1 & 1 \\
\hline كبيرة & 0.58 & 4.08 & التعليمية . لبنية التحتية للمدارس ومديريات المحافظات & 2 & 2 \\
\hline 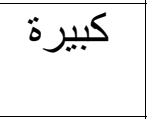 & 0.57 & 4.07 & والمدارس ف في بعض الإنترنت وتوقفان. في المديريات التعليمة & 5 & 3 \\
\hline كبيرة & 0.61 & 3.98 & و المديريات تدعيم الحوليمة اسب بتقنية الإنترنت في المدارس & 2 & 4 \\
\hline متوسط & 0.58 & 3.92 & نقص المعامل التعليمية. المطورة في الحاسب الآلي في & 11 & 5 \\
\hline كبيرة & 0.61 & 3.90 & مؤتمر توات الفيديو. التجهيزات المناسبة للعمل باستخدام & 9 & 6 \\
\hline كبيرة & 0.54 & 3.89 & نقص تو افر البرامج و البرمجيات إلكترونية خاصة. & 3 & 7 \\
\hline كبيرة & 0.66 & 3.85 & هذه التكنولوجيا. تلكان في المحافظات التعليمية لاستخدام & 8 & 8 \\
\hline كبيرة & 0.70 & 3.76 & وصيانته في الكو ادتفظات التعليمية. في أدوات التكنولوجيا & 7 & 9 \\
\hline متوسط & 0.80 & 3.20 & في المحافظات التعليمية. الاتصال بين الأقسام الإدارية و الفنية & 10 & 11 \\
\hline ضعيفة & 0.81 & 2.53 & انقطاع التيار الكهربائي في المديريات التعليمية. & 6 & 10 \\
\hline كبيرة & 0.44 & 3.76 & المستوى العام & & \\
\hline
\end{tabular}

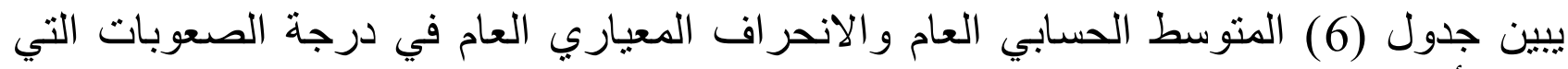
يمكن أن تعترض استخدام مؤتمرات الفيديو (المعوقات المادية)، إذ بلغ المتوسط العارئ العام (3.76)، 
بانحر اف معياري عام (0.44)، بدرجة كبيرة. وهذا يؤكد وجود صعوبات في الإمكانيات المادية

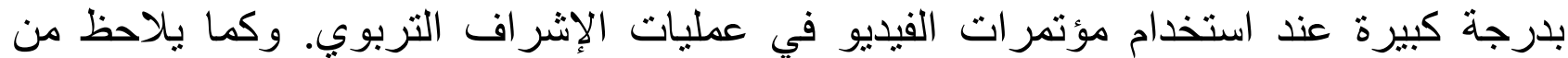

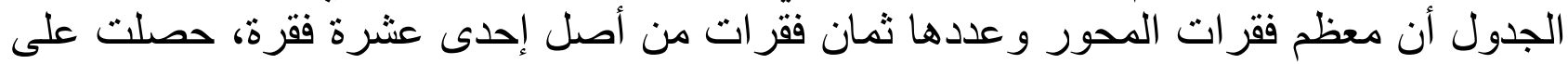

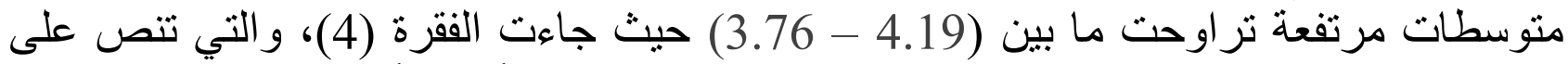

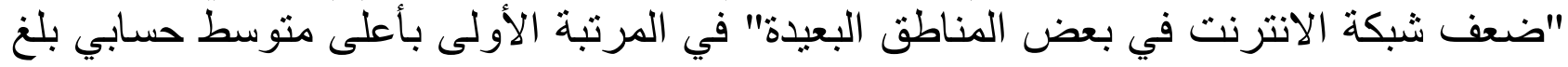

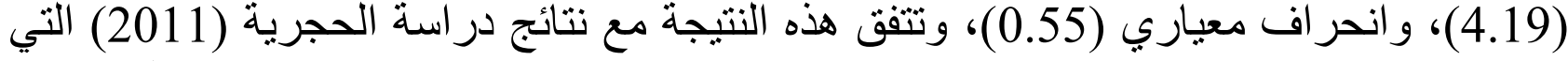

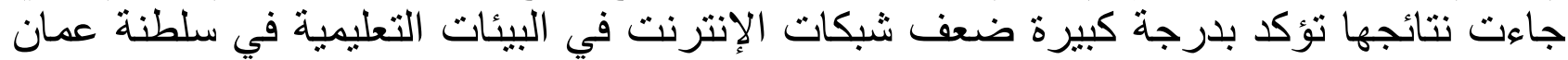

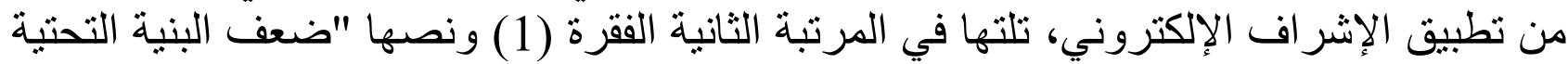

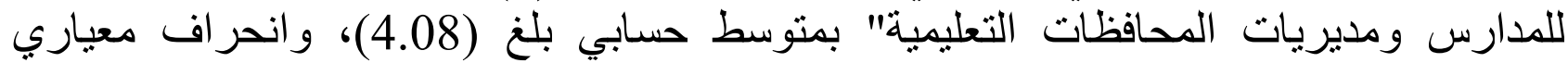

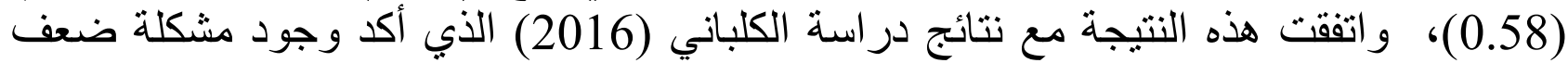

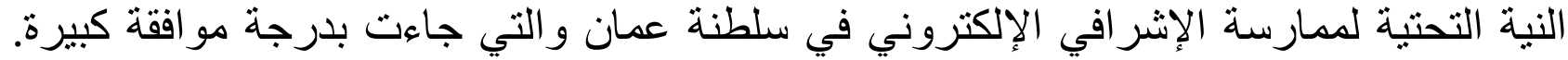

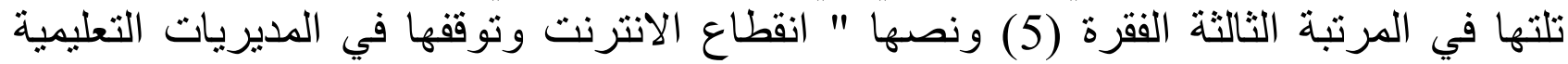

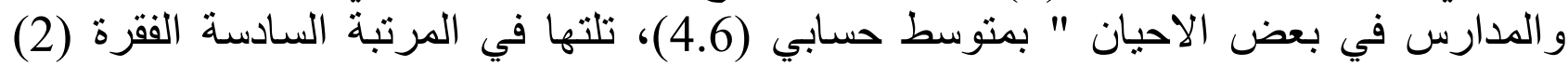

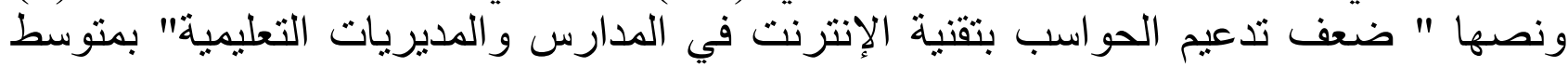

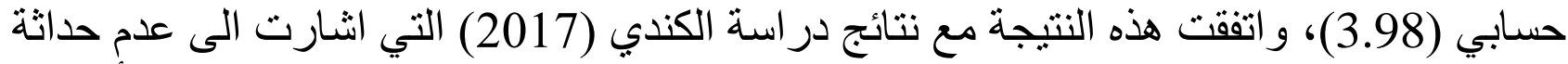

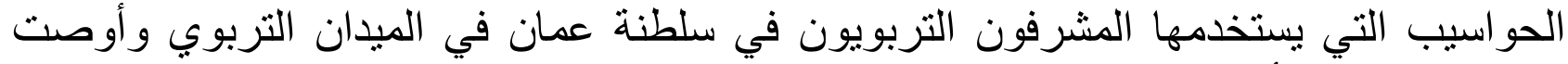
بضرورة توفير الأجهزة المناسبة والمحدثة لمشرفين التربئن التربونين.

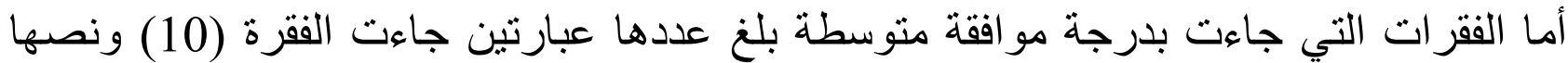

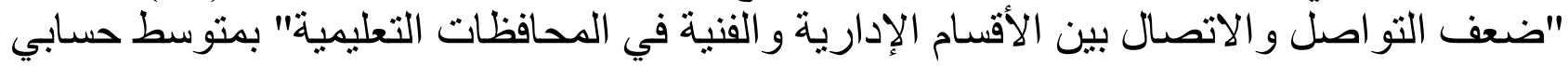

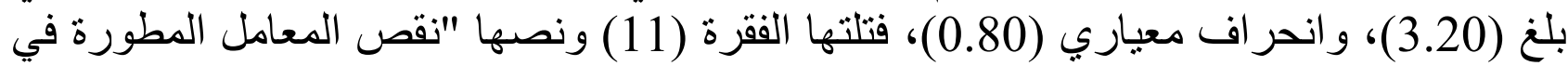
الحاسب الآلي في المديريات التعليمية" بمتوسط حسابي (2017) (3.92). و اتفقت هذه التهات النتائج مع النتيجة التي توصلت إليهاً در اسة الكندي (2017) الذي أثنار أن عدم تو افر الخدمات.

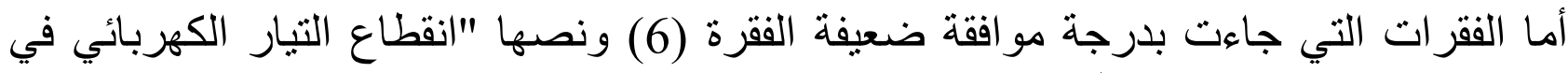

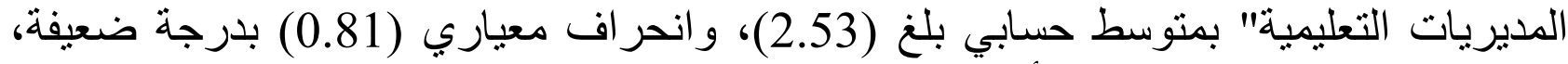

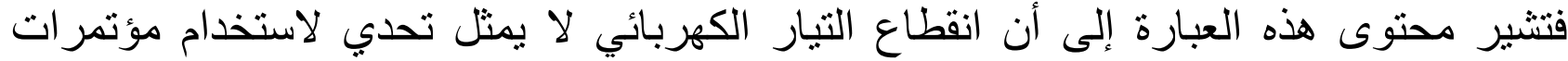

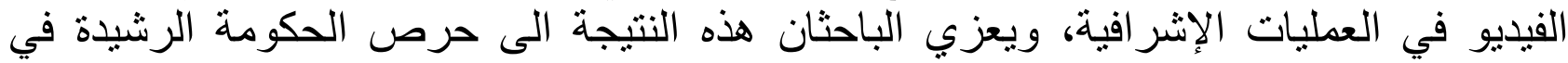

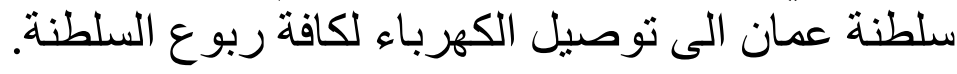
من خلال تحليل مضمون محتوى النتائج السابقة المتعلقة بالمعوقات المبات المادية التي تقلل من استخدام

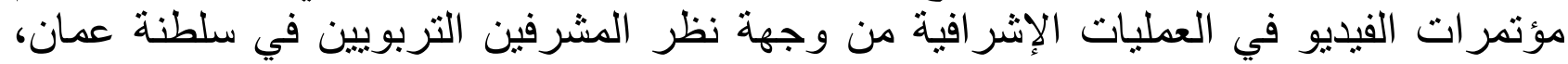

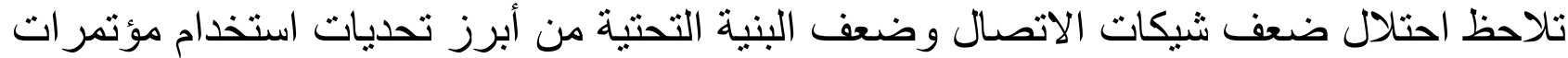

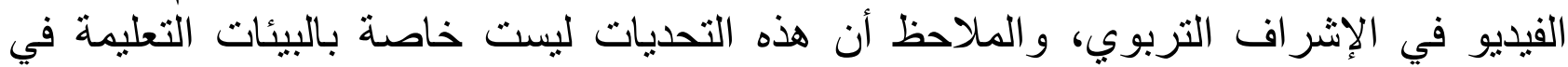

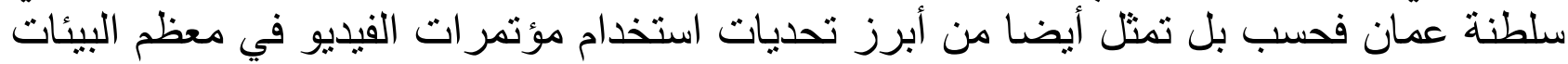

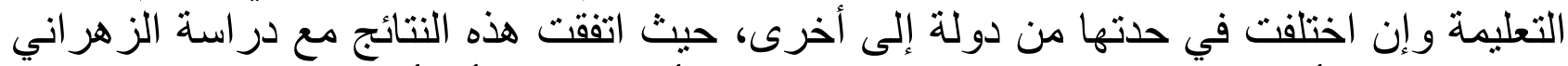

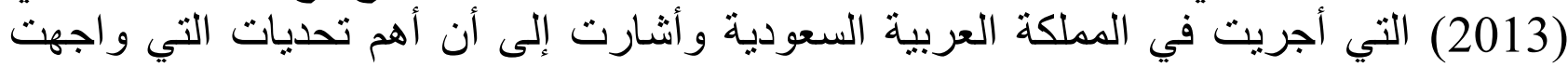
القيادات الإدارية في استخدام مؤتمرات في تنمية المهارات المهنية ضعف إلى إكانية الوصدول 


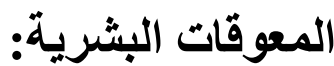

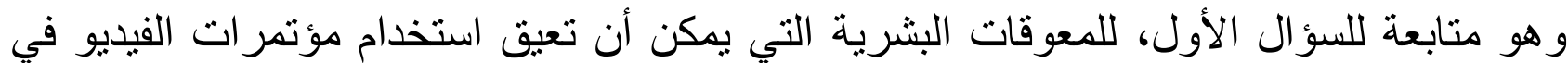

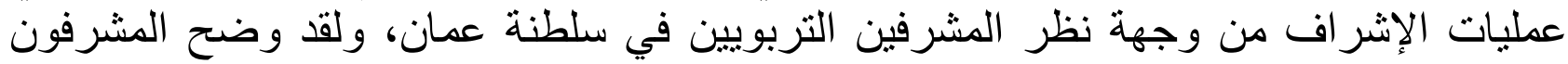

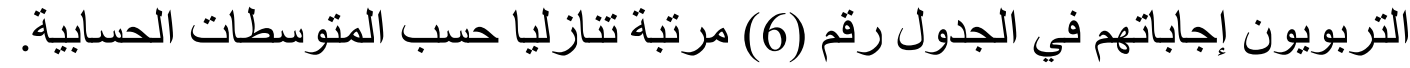

جدول (7) استجابات المشرفين التربويين لتحديد المعوقات البشرية

\begin{tabular}{|c|c|c|c|c|c|}
\hline الارجة & 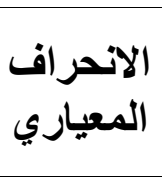 & المتوسد & 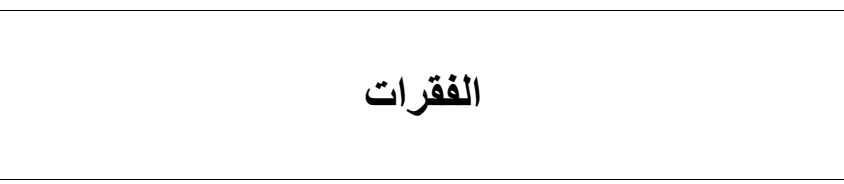 & 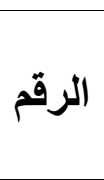 & 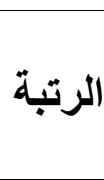 \\
\hline كبيرة & 0.57 & 3.96 & قلة التدريب على توظيف تكنولوجيا مؤتمر ات الفيديو. & 19 & 1 \\
\hline كبيرة & 0.62 & 3.91 & 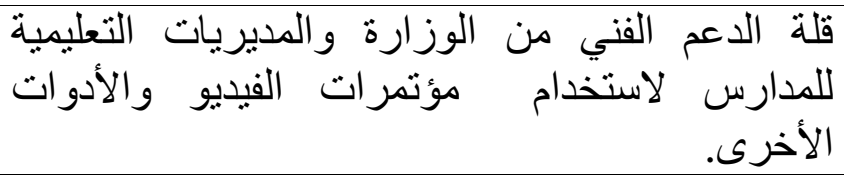 & 20 & 2 \\
\hline كبيرة & 0.66 & 3.78 & التقنيات التكنولو مهار ات المشرفين التربوين الحاسب في استخدام & 14 & 3 \\
\hline متوسط & 0.67 & 3.34 & 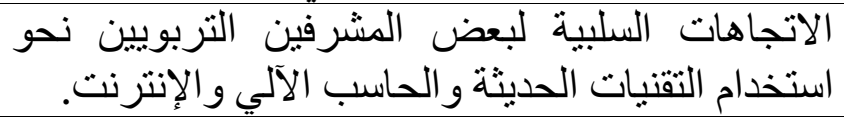 & 13 & 4 \\
\hline متوسط & 0.72 & 3.26 & روالتطوير. بعض المشرفين التربويين بضرورة التغير & 15 & 5 \\
\hline متوسط & 0.67 & 3.11 & تناسب مع إنجاحول نمط الميلون إلى المركزية في العمل، و التي لا لعن & 18 & 6 \\
\hline متوسط & 0.69 & 3.09 & المشرف بوجوده المشرفون بأن محور العملية الإشر افية هو & 12 & 7 \\
\hline متوسط & 0.64 & 3.07 & 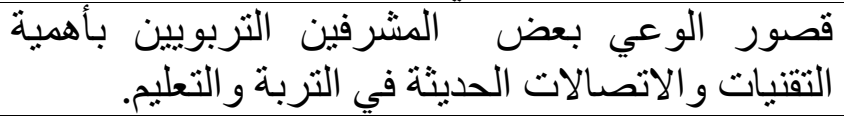 & 17 & 8 \\
\hline متوسط & 0.70 & 3.07 & التكنولو تو افية و الإنترنت و أدواته الكافي $\quad$ لاستخدام التقنيات & 16 & 9 \\
\hline متوسط & 0.44 & 393. & المستوى العام & & \\
\hline
\end{tabular}

تلاحظ من الجدول رقم (7) أن المشرفين التربويين قد وضحوا من خلال استجابتهم لفقرات

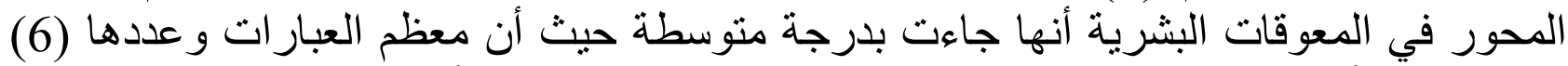

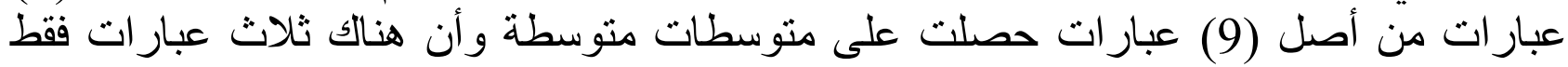

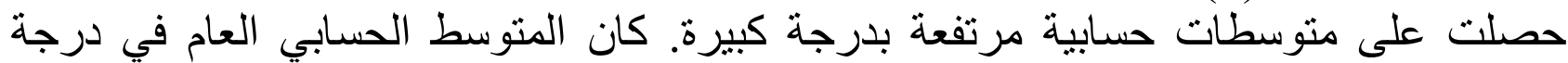

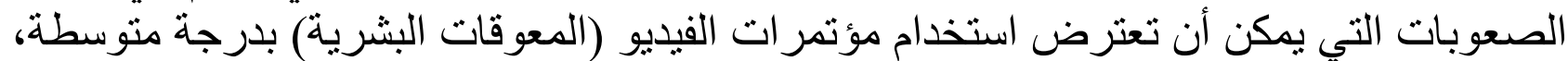

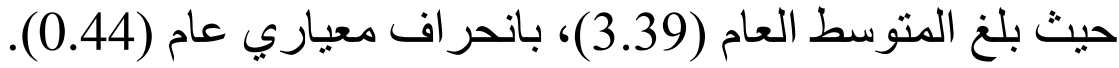

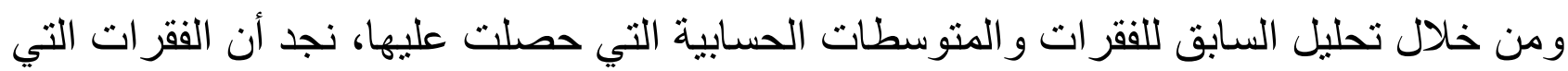

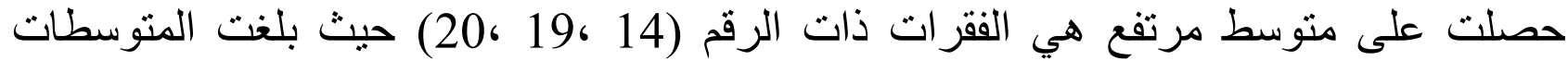
الحسابية (3.96 - 3.78) وبانحر افات معيارية (0.52 - 0.66)، حيث نجد الرفي أن الفقرة (19)، 
و التي تتص على "قلة التدريب على توظيف تكنولوجيا مؤتمر ات الفيديو" في المرتبة الأولى بأعلى وألى

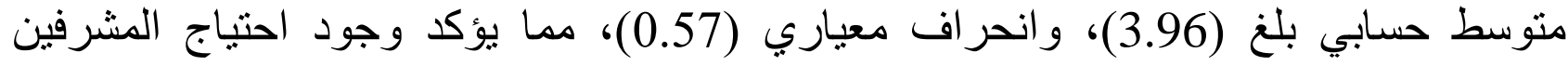

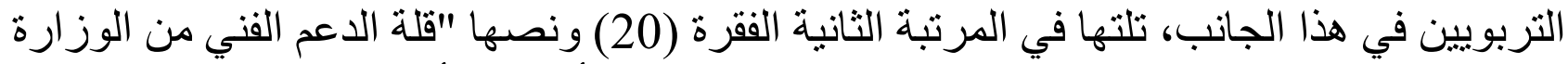

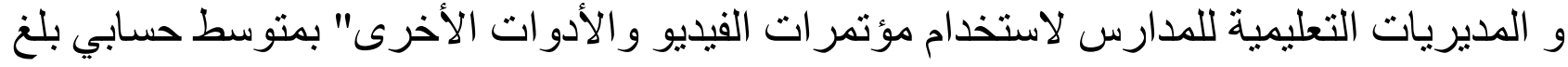

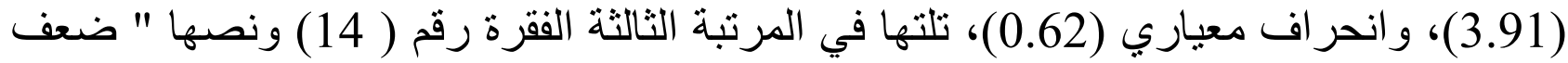

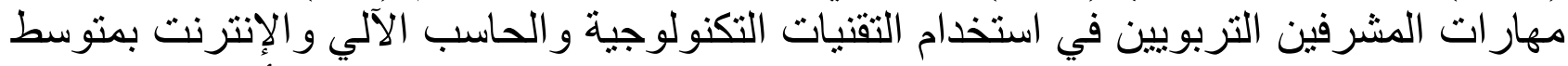

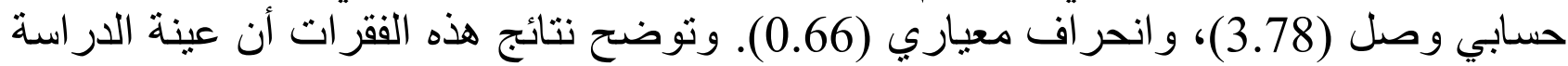

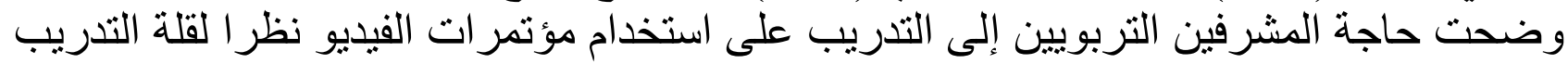

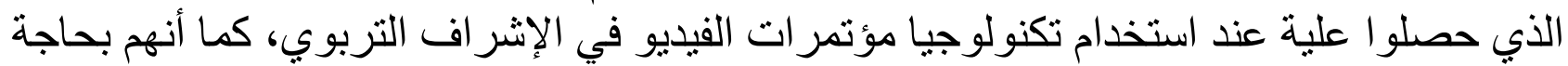

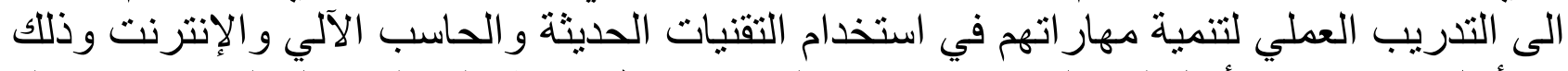
من أجل الاستخدام الأمثل لتكنولوجيا مؤتمر ات الفيديو وتوظيف هذه التفئ التقنية في العمليات الإشر افية.

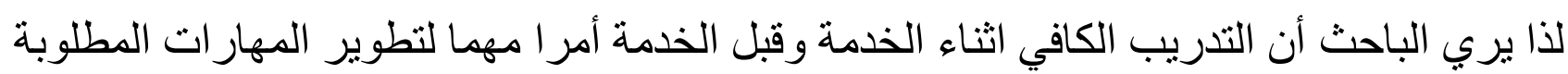

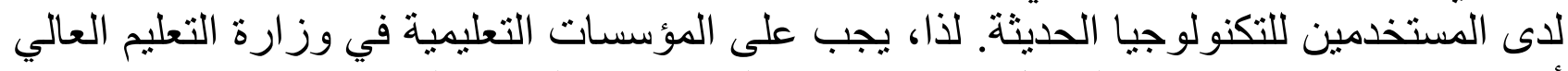

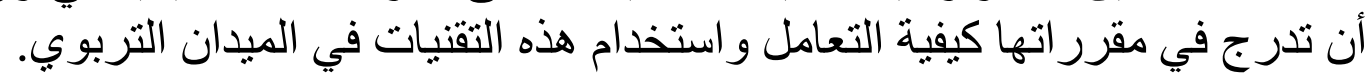

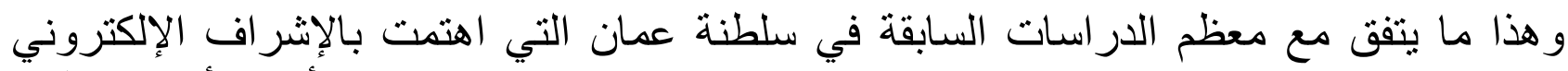

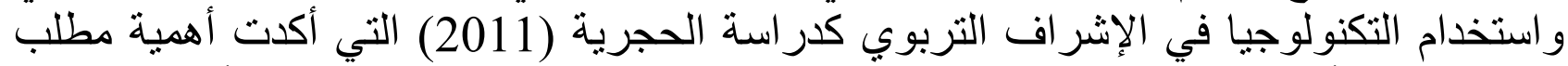

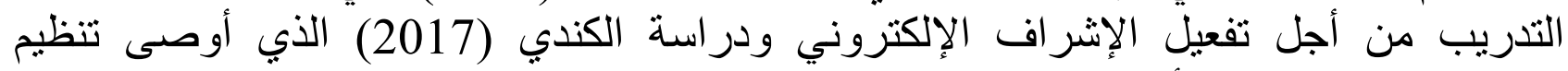
الملتقيات و الدور ات من أجل تعميق المتابعة الإشر افية الإلكترونية.

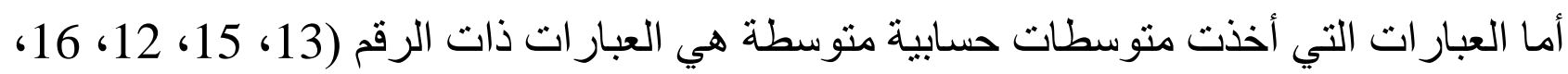

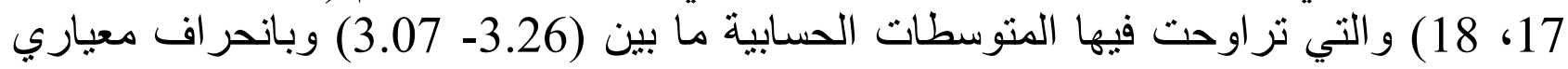

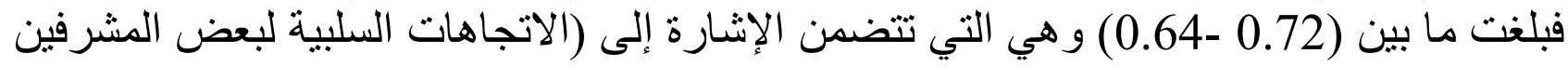

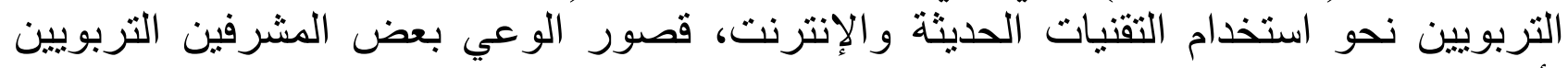

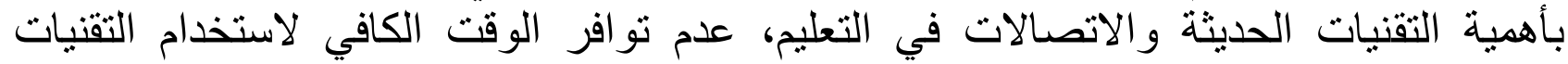

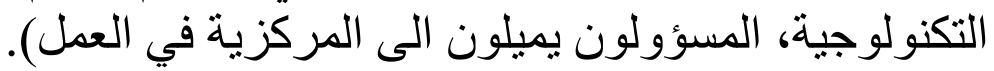

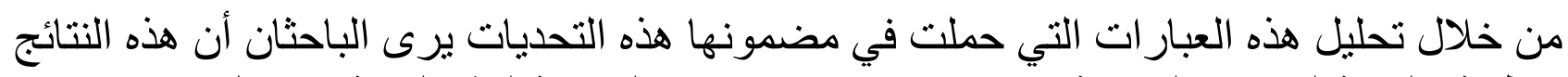

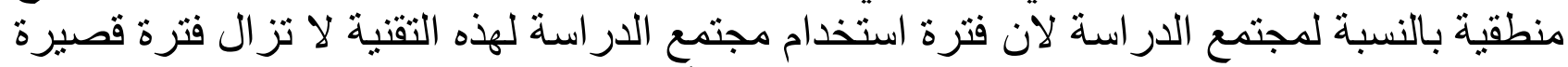

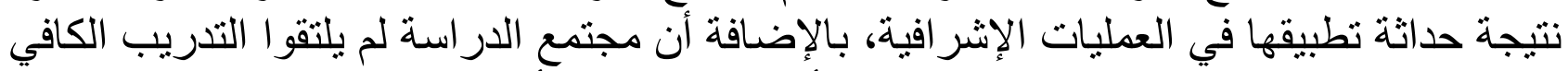

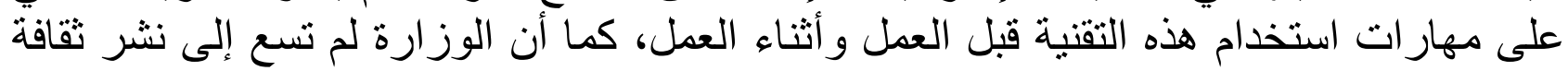

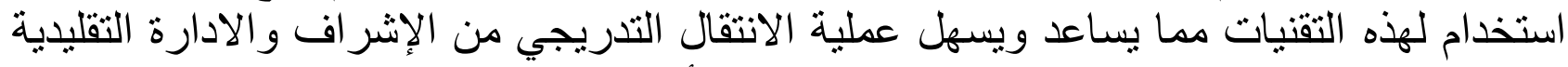

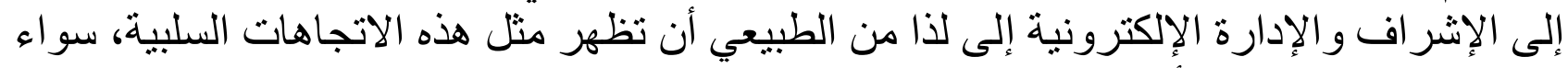

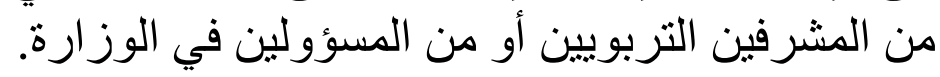
خاتمة وتوصيات الدراسة:

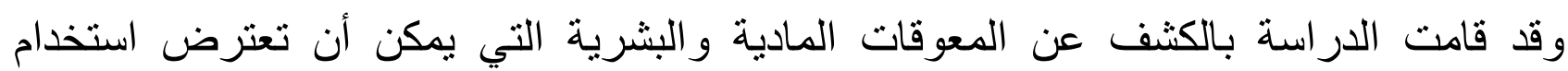

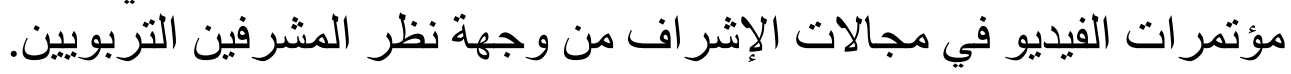
وفي ضوء نتائج الدر اسة، يوصي الباحثنان بما يأتي: 
- تقوية شبكات الانترنت و الاتصال في المديريات التعليمية وفي المدارس حتى تيح للمشرف من استخدام تقنية مؤتمر ات الفيديو.

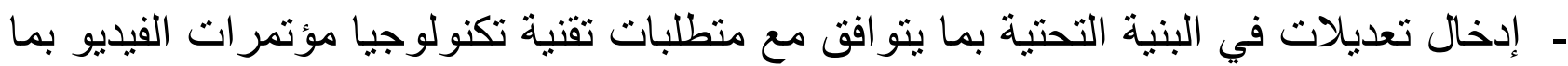

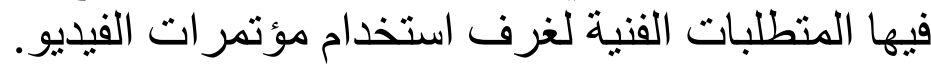

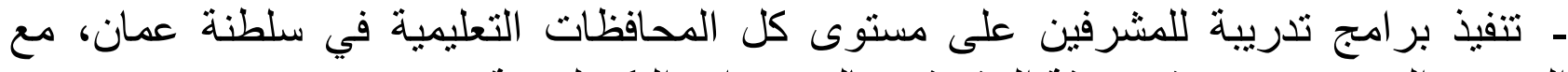
التدريب المستمر وتحديث معرفة المشرفين بالمستجدات التكنولوجية.

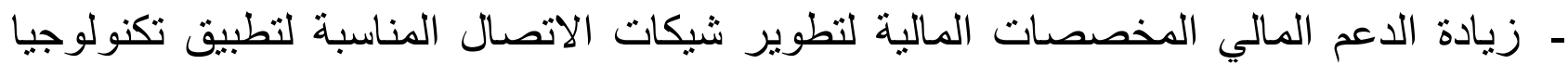
مؤتمر ات الفيديو.

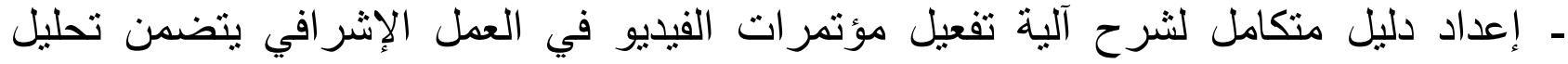
ودر اسة العو امل النفسية و التقنية و المادية التي تو اجه تفعيل مؤتثر اتفرات الفيديو.

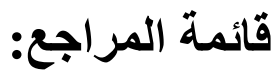

الأغا، إحسان. (1997). البحث التربوي "أدو اته مناهجه، و عناصره". مطبعة الرنتيسي: غزة.

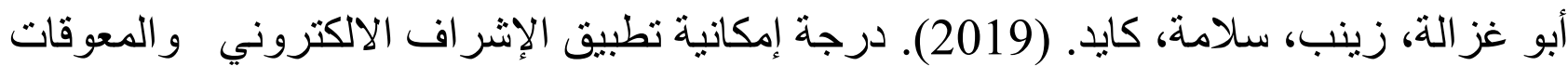

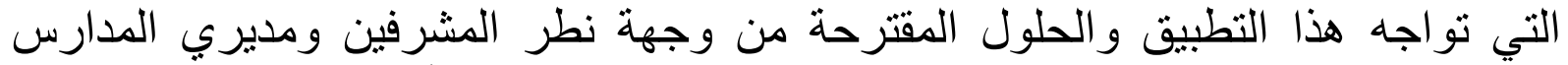

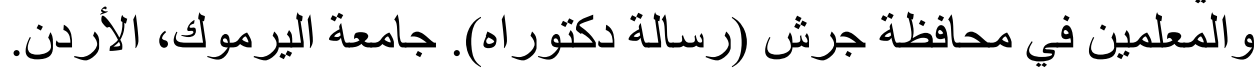

البشابشة، رنا إبر اهيم. (2014). مدى استخدام المشرفيين التربويين لتطبيقات تكنولوجيا المعلومات والاتصالات في المدارس الثانوية و المعيقات التي تحد من استخدامها في محافظة

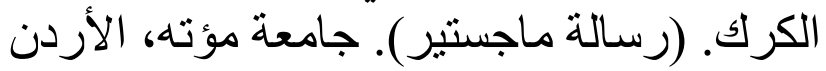

الحجرية، نعيمة. (2011). إمكانية تطبيق الإشر اف الإلكتروني في وزارة التربية والتعليم بسلطنة عمان. (رسالة ماجستير غير منشورة). جامعة السلطان قابوس، سلطنة عمان.

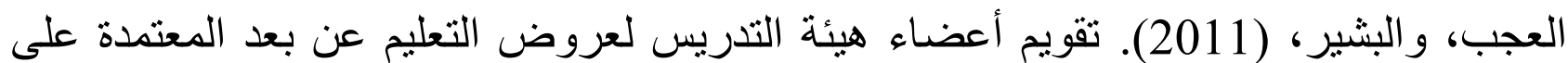

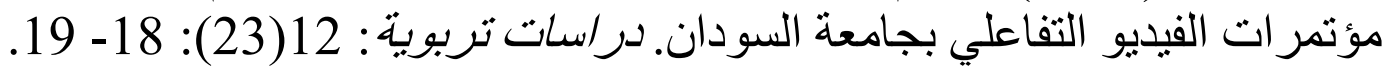
الزهراني، هند، هارون، الطيب أحمد. (2013). فاعلية مؤتمرات الفيديو في تنمية الكفايات

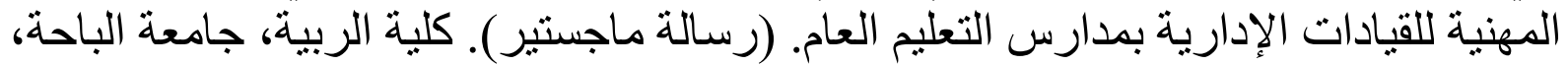
المملكة العربية السعودية.

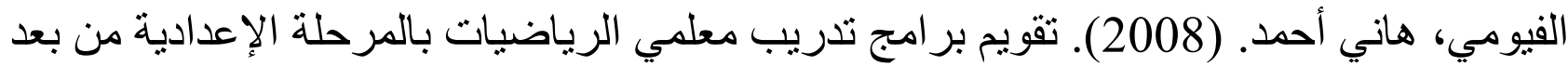

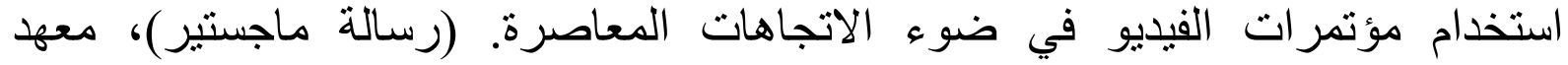
الدر اسات و البحوث التربوات الفية، جامعة القاهرة، مصر.

القرني، عبير. (2014). تكنولوجيا مؤتمر ات الفيديو للتعليم عن بعد في المملكة العربية السعودية: المشكلات الحالية، و الحلول الممكنة. (رسالة دكتور اه)، كلية الهندسة و وعلوم الحولية الحوسبة، جامعة

$$
\text { در هام. }
$$




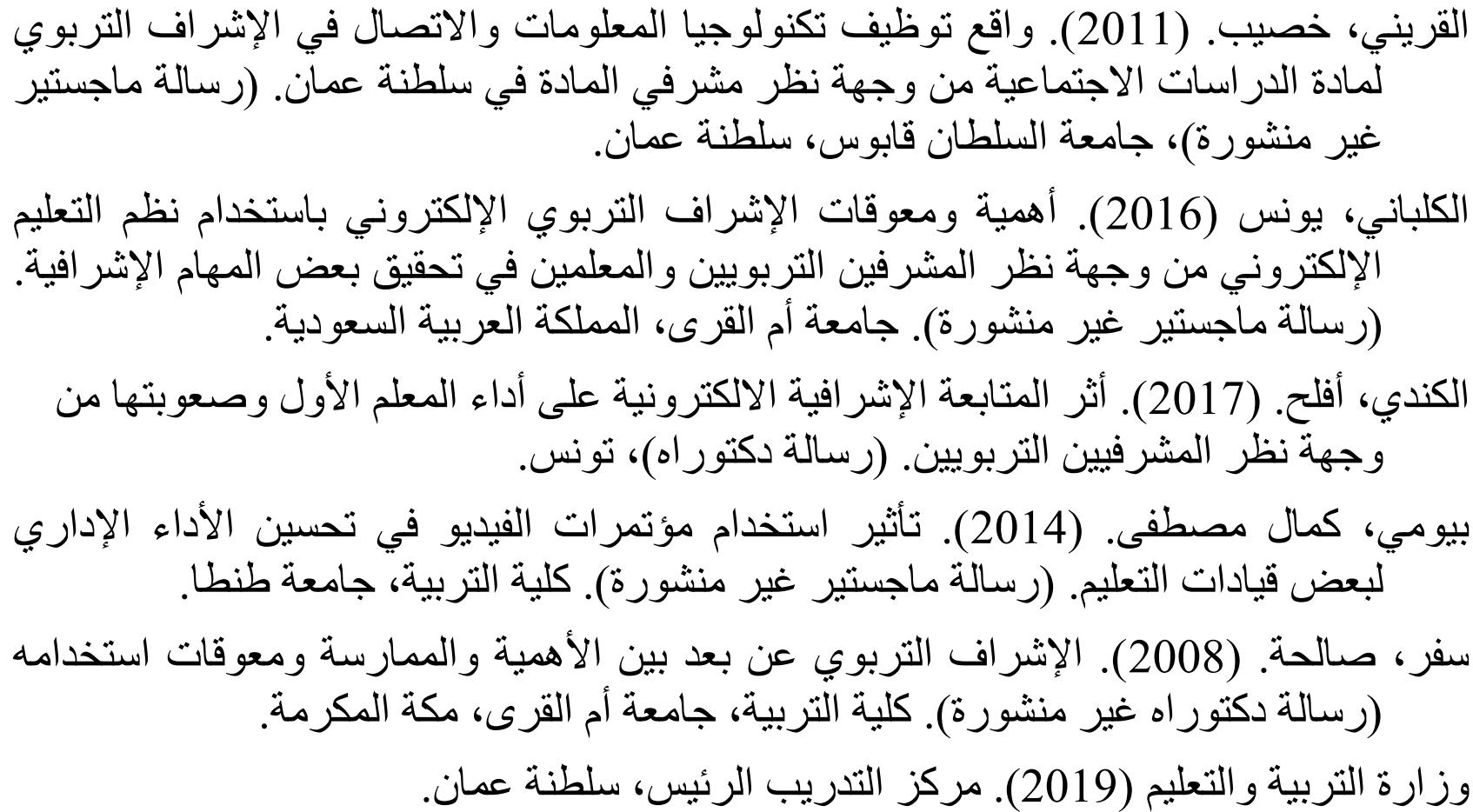

\section{ARABIC REFERENCES IN ROMAN ALPHABETS}

Al'agha, 'lihsan. (1997). Albahth Altarbawi "Adawath Manahijh, Waeanasrha". Mutbaeat Alrantisi: Ghazat. 'Abu Ghazalat,

Zinab, Salamat, Kayd. (2019). Darajat 'limkaniat Tatbiq Al'iishraf Al'iiliktrunii Walmueawiqat Alty Tuajih Hdha Altatbiq Walhulul Almuqtarahat Min Wijhat Natar Almushrifayn Wamudiri Almadaris Walmuelimin Fi Muhafazat Jarash (Rsalat Dukturaha). Jamieat Alyrmwk, Al'urdunn.

Albashabshat, Rana 'librahim. (2014). Madaa Aistikhdam Almashrifiiyn Altarbuiiyn Litatbiqat Tiknulujia Almaelumat Walaitisalat Fi Almadaris Alththanawiat Walmeyqat Alty Tahadu Min Aistikhdamuha Fi Muhafazat Alkrk. (Rsalt Majstyr). Jamieatan Muth, Al'urdun

Alhajriat, Naeimut. (2011). 'limkaniat Tatbiq Al'iishraf Al'iliktrunii Fi Wizarat Altarbiat Waltaelim Bisiltanat Eumaana. (Rsalat Majstayr Ghyr Minshurta). Jamieat Alsultan Qabus, Saltanat Eaman.

Aleujb, Walbashir, (2011). Taqwim 'Aeda' Hayyat Altadris Lieurud Altaelim Ean Baed Almuetamadat Ealaa Mutamarat Alfidyu Altafaealii Bijamieat Alsuwdan. Dirasat Tarbawit: 12(23): 18- 19.

Alzahraniu, Hanad, Harun, Altayib 'Ahmud. (2013). Faeiliat Mutamarat Alfidyu Fi Tanmiat Alkifaayat Almihniat Lilqiadat Al'iidariat Bimadaris Altaelim Aleami. (Rsaalat Majstayr). Kuliyat Alrabyt, Jamieat Albahati, Almamlakat Alearabiat Alsaeudiat.

Alfiumi, Hani 'Ahmud. (2008). Taqwim Baramij Tadrib Muelimii Alriyadiaat Bialmarhalat Al'iiedadiat Min Baed Aistikhdam Mutamarat Alfidyu Fi Daw' Alaitijahat Almueasirati. (Rsaalat Majstyr), Maehad Aldirasat Walbihwith Altarbawiati, Jamieat Alqahirat, Misr.

Alqirni, Eubayr. (2014). Tiknulujia Mutamarat Alfidyu Liltaelim Ean Baed Fi Almamlakat Alearabiat Alsaeudiati: Almushkilat Alhaliati, Walhulul Almumkinatu. (Rsaalat Dukturah), Kuliyat Alhindasat Waeulum Alhusibat, Jamieat Dirham.

Alqariniu, Khusib. (2011). Waqie Tawzif Tuknulujia Almaelumat Walaitisal Fi Al'iishraf Altarbuii Limadat Aldirasat Alaijtimaeiat Min Wijhat Nazar Musharifi Almadat Fi Saltanat Eumaana. (Rsalat Majstayr Ghyr Minshurata), Jamieat Alsultan Qabus, Saltanat Eaman.

Alkulbani, Yunis (2016). 'Ahamiyat Wamueawiqat Al'iishraf Altarbawii Al'iiliktrunii Biastikhdam Nazam Altaelim Al'iiliktrunii Min Wijhat Nazar Almushrifin Altarbuiiyn Walmuelimin Fi Tahqiq Bed Almahami Al'iishrafiati. (Rsaalat Majstayr Ghyr Minshurta). Jamieat 'Am Alquraa, Almamlakat Alearabiat Alsaeudiat.

Alkanadi, 'Afluh. (2017). 'Athar Almutabaeat Al'iishrafiat Al'iiliktruniat Ealaa 'Ada' Almuelim Al'awal 
Wasueubatiha Min Wijhat Nazar Almashrifiiyn Altaribuwiiyna. (Rsalat Dukturah), Tuns.

Biawmi, Kamal Mustafaa. (2014). Tathir Aistikhdam Mutamarat Alfidyu Fi Tahsin Al'ada' Al'iidarii Libaed Qiadat Altaelimi. (Rsaalat Majstayr Ghyr Minshurata). Kuliyat Altarbiati, Jamieatan Tintaan.

Safir, Salihat. (2008). Al'iishraf Altarbwiu Ean Baed Bayn Al'ahamiyat Walmumarasat Wamueawiqat Aistikhdamih (Rsalat Dukturah Ghyr Minshurta). Kuliyat Altarbiati, Jamieat 'Am Alquraa, Makat Almukramat.

Wizarat Altarbiat Waltaelim (2019). Markaz Altadrib Alrayiysu, Saltanat Eaman.

\section{REFERENCES}

Joffrion, L. C. (2014). Video conferencing in the High School Classroom: Application of the concern-Based Adoption Model Information Technology Service: What is Video-Conferencing? (Doctoral dissertation). University of Capella the Faculty of the Education Department Carson-Newman University. 